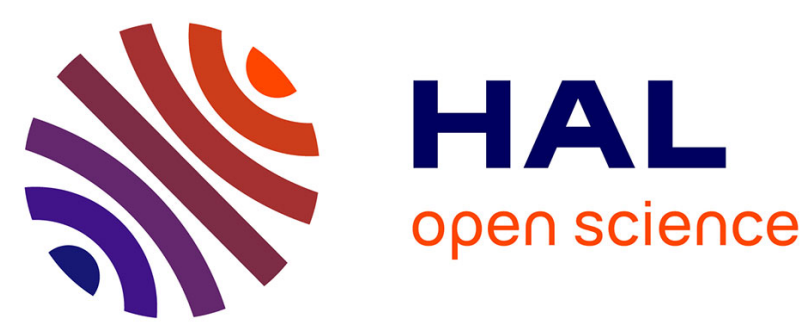

\title{
Nitroxide-Mediated Polymerization-Induced Self-Assembly of Block Copolymers at the Surface of Silica Particles: Toward New Hybrid Morphologies
}

X. Qiao, O. Lambert, J.-C. Taveau, Pierre-Yves Dugas, Bernadette Charleux, Muriel Lansalot, Elodie Bourgeat-Lami

\section{To cite this version:}

X. Qiao, O. Lambert, J.-C. Taveau, Pierre-Yves Dugas, Bernadette Charleux, et al.. NitroxideMediated Polymerization-Induced Self-Assembly of Block Copolymers at the Surface of Silica Particles: Toward New Hybrid Morphologies. Macromolecules, 2017, 50 (10), pp.3796 - 3806. 10.1021/acs.macromol.7b00033 . hal-01716039

\author{
HAL Id: hal-01716039 \\ https://hal.science/hal-01716039
}

Submitted on 7 Oct 2021

HAL is a multi-disciplinary open access archive for the deposit and dissemination of scientific research documents, whether they are published or not. The documents may come from teaching and research institutions in France or abroad, or from public or private research centers.
L'archive ouverte pluridisciplinaire HAL, est destinée au dépôt et à la diffusion de documents scientifiques de niveau recherche, publiés ou non, émanant des établissements d'enseignement et de recherche français ou étrangers, des laboratoires publics ou privés. 


\title{
Nitroxide-mediated polymerization-induced self-assembly
}

\section{of block copolymers at the surface of silica particles:}

\section{Towards new hybrid morphologies}

\author{
X. G. Qiao, ${ }^{1,2}$ O. Lambert, ${ }^{3}$ J-C. Taveau, ${ }^{3}$ P-Y. Dugas, ${ }^{1}$ B. Charleux, ${ }^{1}$ M. Lansalot,${ }^{1}$ \\ E. Bourgeat-Lami ${ }^{1 *}$
}

\begin{abstract}
${ }^{1}$ Univ Lyon, Université Claude Bernard Lyon 1, CPE Lyon, CNRS, UMR 5265, Chemistry, Catalysis, Polymers and Processes (C2P2), 43 Bvd. du 11 Novembre 1918, F-69616 Villeurbanne, France. ${ }^{2}$ College of Chemistry and Chemical Engineering, Henan Key laboratory of Function-Oriented Porous Materials, Luoyang Normal University, Luoyang 471934, China. ${ }^{3}$ Université de Bordeaux, CNRS, CBMN, UMR 5248, F-33600 Pessac, France.
\end{abstract}

\begin{abstract}
Silica/polymer latexes with concentric core-shell-corona, half-capped, snowman-like vesicular, tadpole- and centipede-like morphologies have been produced by nitroxidemediated polymerization-induced self-assembly (PISA) performed in the presence of aqueous suspensions of colloidal silica. A hydrosoluble brush-like PEO-based macroalkoxyamine $\left(\mathrm{P}\left[(\text { poly (ethylene oxide) methyl ether methacrylate })_{12}\right.\right.$-co-styrene $]-\mathrm{SG} 1, M_{\mathrm{n}}=11700 \mathrm{~g} \mathrm{~mol}^{-1}$ and $M_{\mathrm{w}} / M_{\mathrm{n}}=1.11$ ) was first adsorbed onto the surface of submicronic silica particles. The obtained suspension was then used in the emulsion polymerization of $n$-butyl methacrylate with $8 \mathrm{~mol} \%$ of styrene. This led to the formation of amphiphilic block copolymers (BCPs) that self-assembled in situ at the silica surface into well-defined hybrid nano-object of various morphologies, in agreement with the principles of polymerization-induced micellization. The influence of the $\mathrm{pH}$ was more specifically investigated, using silica particles of different size ranging from 30 to $230 \mathrm{~nm}$. This parameter was shown to have a significant effect on particle
\end{abstract}


morphology. Indeed, while multipod-like particles were obtained below pH 6 regardless of the silica particle size, polymerizations conducted at higher $\mathrm{pH}$ values led to unconventional morphologies that have never been reported before. Silica-armored fibers and/or vesicles were obtained for the smallest silica particles $\left(D_{\mathrm{n}}=30 \mathrm{~nm}\right)$ whereas larger silica beads $\left(D_{\mathrm{n}}=\right.$ $230 \mathrm{~nm}$ ) predominantly led to core-shell particles. More interestingly, the use of an intermediate silica particle size $\left(D_{\mathrm{n}}=136 \mathrm{~nm}\right)$ led to a complex mixture of kineticallytrapped copolymer morphologies. For the first time, cryo-electron tomography (cryo-ET) of the sample provided direct observation of the 3D structures and furthermore gave insights into the self-assembly process as intermediate morphologies were also captured.

Keywords: Silica, RDRP, emulsion polymerization, PISA, amphiphilic block copolymers, nitroxide-mediated polymerization, PEGMA, morphology, cryo-electron tomography. 


\section{INTRODUCTION}

Organic/inorganic hybrid colloids (also called colloidal nanocomposites) are an attractive type of composite materials that can find application in many different fields, for instance in emulsion paints, optics and biology. ${ }^{1}$ The incorporation of inorganic particles into polymeric matrices allows combining the best advantages of inorganic solids (mechanical strength, thermal stability and unique physical properties) with the processability and flexibility of organic polymers. A variety of approaches have been reported in the literature to synthesize these materials, including heterocoagulation, layer-by-layer assembly and in situ polymerization. ${ }^{1}$ In this last technique, monomers are polymerized in the presence of inorganic colloidal particles. $^{2}$ Emulsion polymerization, a widely used free radical polymerization process, is undoubtedly one of the most popular methods to synthesize colloidal nanocomposites via in situ polymerization. ${ }^{3}$ In a typical process, the inorganic particles are dispersed in the aqueous phase, and their surface is functionalized to favor the capture of the growing macromolecules, leading to various morphologies depending on the inorganic particles surface properties and the polymerization conditions. However, in most of the strategies reported, the use of surfactants is required to provide colloidal stability to the hybrid particles although it is known that surfactant molecules can migrate in the final materials and adversely affect film formation and properties.

Recently, Hawkett et al. ${ }^{4}$ pioneered a versatile approach involving the use of reversible deactivation radical polymerization (RDRP) for the surfactant-free synthesis of hybrid latex particles in aqueous dispersed media. ${ }^{5,6}$ This strategy relies on the use of living amphipathic random copolymers, capable of interacting with the surface of inorganic particles or organic pigments, to favor their encapsulation through emulsion polymerization. The hydrophilic monomer units in the copolymer provide colloidal stability to the resulting core-shell particles, while its random nature ensures that the controlling agent does not form micelles in 
water, thereby minimizing secondary nucleation. Finally, the incorporation of hydrophobic units in the living chains increases the affinity of the hydrophobic monomers for the particle's environment, promoting the formation of an encapsulating shell. The approach has been successfully used for the polymer encapsulation of a large variety of particles ranging from metal oxides (e.g. titanium dioxide, ${ }^{4}$ cerium oxide, ${ }^{7}$ iron oxide, ${ }^{8}$ silica ${ }^{9}$ ), organic pigments, ${ }^{4}$ to carbon nanotubes,${ }^{10}$ graphene oxide ${ }^{11}$ and bidimensional clay platelets such as gibbsite, ${ }^{12}$ Montmorillonite ${ }^{13}$ and layered double hydroxides. ${ }^{14}$ One of the key benefits of this technique is that it does not require any chemical functionalization of the inorganic surface or the use of molecular surfactants. Although until now the attention has been dedicated almost exclusively to the use of reversible addition-fragmentation chain transfer (RAFT), ${ }^{5}$ the approach was recently expanded to nitroxide-mediated polymerization (NMP) ${ }^{15}$ and atom transfer radical polymerization (ATRP). ${ }^{16}$ Irrespective of the RDRP technique used, the main purpose of these works was to encapsulate the inorganic particles or the organic pigments by taking advantage of the living character of the polymer chains that can be reactivated during emulsion polymerization. Indeed, the key role of the control agent is its provision of many active sites for chain growth, and its capability to effectively control the polymerization was generally considered of less importance. ${ }^{17}$ However, we ${ }^{15,18}$ and others ${ }^{4,12,19}$ showed that well-defined amphiphilic block copolymers (BCPs) can also be obtained concomitantly to the successful formation of hybrid particles, according to the so-called polymerization-induced self-assembly (PISA) process.

The PISA process has been used with success for various RDRP systems under aqueous emulsion $^{20}$ or dispersion ${ }^{21,22}$ polymerization conditions, and can lead to a wide variety of nanostructures (spheres, rods, fibers, lamella or vesicles) depending on the nature and molar mass of both the hydrophobic and hydrophilic blocks, and the solids content or the physicochemical parameters of the dispersed phase (i.e. $\mathrm{pH}$, ionic strength, temperature, 
etc.). ${ }^{5}$ Besides, various authors have observed a gradual change of particle morphology from spheres to worms to vesicles upon increasing the molar mass of the hydrophobic block either in the course of the polymerization, or at full conversion by varying the control agent concentration. Drastic changes in particle morphology have also been observed by varying the nature, the size or the shape of the hydrophilic block. ${ }^{23}$ Based on the different morphologies already achieved through the PISA process, it can be anticipated that the synthesis of BCPs in the presence of inorganic particles could provide more complex selfassembled structures.

We recently reported the first $N$-tert-butyl- $N$-(1-diethyl phosphono-2,2-dimethylpropyl) nitroxide (SG1)-mediated synthesis of multipod-like silica/polymer latexes through BCPs self-assembly in aqueous emulsion. ${ }^{15}$ To that purpose, a brush-type PEO-based macroalkoxyamine initiator $\left(\mathrm{P}\left[\left(\mathrm{PEOMA}_{950}\right)_{12}-c o\right.\right.$-styrene $]-\mathrm{SG} 1$ was adsorbed at the surface of silica particles, and used to initiate the growth of the hydrophobic block - composed of $n$ butyl methacrylate (BMA) and a small amount of styrene (S) - directly in aqueous emulsion in the absence of surfactant. Varying the silica particle size or macroinitiator concentration led to the formation of composite particles with snowman-, daisy- and raspberry-like morphologies. Furthermore, size exclusion chromatography (SEC) analyses showed a shift of the molar mass with conversion in agreement with a controlled polymerization process. In the present study, we were further interested in studying the effect of $\mathrm{pH}$, a parameter that already proved to strongly influence the morphology of the self-assembled BCPs in the absence of silica. ${ }^{24}$ While multipod-like silica/polymer composite particles were obtained below $\mathrm{pH}$ 6, increasing the suspension $\mathrm{pH}$ led to unconventional morphologies such as concentric core-shell-corona, half-capped, snowman-like vesicles, tadpoles and centipedes depending on the silica particle size. Cryo-electron tomography was used for the first time to visualize the 3D-structure of the composite particles formed in the presence of silica particles 
of approximately $136 \mathrm{~nm}$ in diameter. Various intermediate morphologies could be clearly evidenced providing insights into the mechanism of particle formation and the morphological changes occurring at the silica surface under basic conditions, and notably the worm-tovesicle transition.

\section{EXPERIMENTAL SECTION}

Materials. The monomers, styrene (S, 99\%, Acros), n-butyl methacrylate (BMA, 99\%, Aldrich) and poly(ethylene oxide) methyl ether methacrylate $\left(\mathrm{PEOMA}_{950}, M_{\mathrm{n}}=950 \mathrm{~g} \mathrm{~mol}^{-1}\right.$, Aldrich) were used as received. The $N$-(2-methylpropyl)- $N$-(1-diethylphosphono-2,2dimethylpropyl)-O-(2-carboxyl prop-2-yl) hydroxylamine initiator (BlocBuilder $\left.{ }^{\circledR}, 99 \%\right)$ and $N$-tert-butyl- $N$-(1-diethyl phosphono-2,2-dimethylpropyl) nitroxide (SG1, 85\%) were kindly supplied by Arkema. Ethanol (Prolabo, 99.9\%), L-arginine ( $\geqq 98.5 \%$, Aldrich), hydrochloric acid ( $\mathrm{HCl}, 0.1 \mathrm{M}$ solution in water), sodium hydroxide ( $0.1 \mathrm{M}$ solution in water), ammonium hydroxide (28\% wt/wt aqueous ammonia solution, Aldrich), tetraethyl orthosilicate (TEOS, $\geqq 99.0 \%$, Aldrich) and 3-(methacryloxy)propyl trimethoxy silane ( $\gamma$-MPS, 98\%, Aldrich) were used without further purification. Deionized water (Purelab Classic UV, ElgaLabWater) was used for all experiments.

Synthesis of silica particles. Submicronic silica particles 30, 136 and $230 \mathrm{~nm}$ in diameter, and with very narrow size distributions were synthesized as reported previously. ${ }^{15}$ Ultrafine silica particles $\left(D_{\mathrm{n}}=30 \mathrm{~nm}\right)$ were synthesized using the two-phase process of Hartlen et al. ${ }^{25}$ In a typical procedure, L-arginine (Aldrich, $26.3 \mathrm{mg}, 6 \mathrm{mmol} \mathrm{L}^{-1}$ ) was first diluted in deionized water $(25 \mathrm{~g})$, charged into the reactor and kept stirring for several minutes with a stirring bar. The temperature was increased to $60{ }^{\circ} \mathrm{C}$, and $4.0 \mathrm{~mL}$ of TEOS was carefully introduced on top of the reactor leading to two separate phases. The stirring rate was fixed at 
$250 \mathrm{rpm}$ so that the top organic layer was left almost undisturbed and the water phase could be well mixed. The mixture was stirred at $60{ }^{\circ} \mathrm{C}$ for $72 \mathrm{~h}$ to form silica particles $30 \mathrm{~nm}$ in diameter. Larger monodisperse particles were obtained from these small silica seeds according to the so-called seed-regrowth process. ${ }^{26}$ In a typical regrowth reaction, the silica seed $(0.02 \mathrm{M})$ was gently dispersed in an ethanol solution containing water and ammonia (0.3 M). Upon uniform mixing, $42.0 \mathrm{~g}$ of TEOS $(1.0 \mathrm{M})$ was added. The mixture was stirred at room temperature for $24 \mathrm{~h}$ to get silica particles $136 \mathrm{~nm}$ in diameter. Finally, larger particle sizes were obtained using the conventional Stöber process in batch. ${ }^{27}$ Typically TEOS $(29.12$ $\mathrm{g}, 0.2 \mathrm{M})$, deionized water (75.6 g, $6 \mathrm{M})$ and absolute ethanol (450 g, $13.9 \mathrm{M})$ were mixed at the beginning of the reaction, charged into a $1 \mathrm{~L}$ round bottom flask and stirred for $20 \mathrm{~min}$. A mixture of ammonia and ethanol (ammonia solution diluted in $15 \mathrm{~g}$ of absolute ethanol, 0.3 M) was introduced at once on the top of the flask and stirred for at least $24 \mathrm{~h}$ at room temperature to get $230 \mathrm{~nm}$ diameter silica particles. Figure 1 shows the transmission electron microscopy (TEM) images and size histograms of the silica particles used in this work.
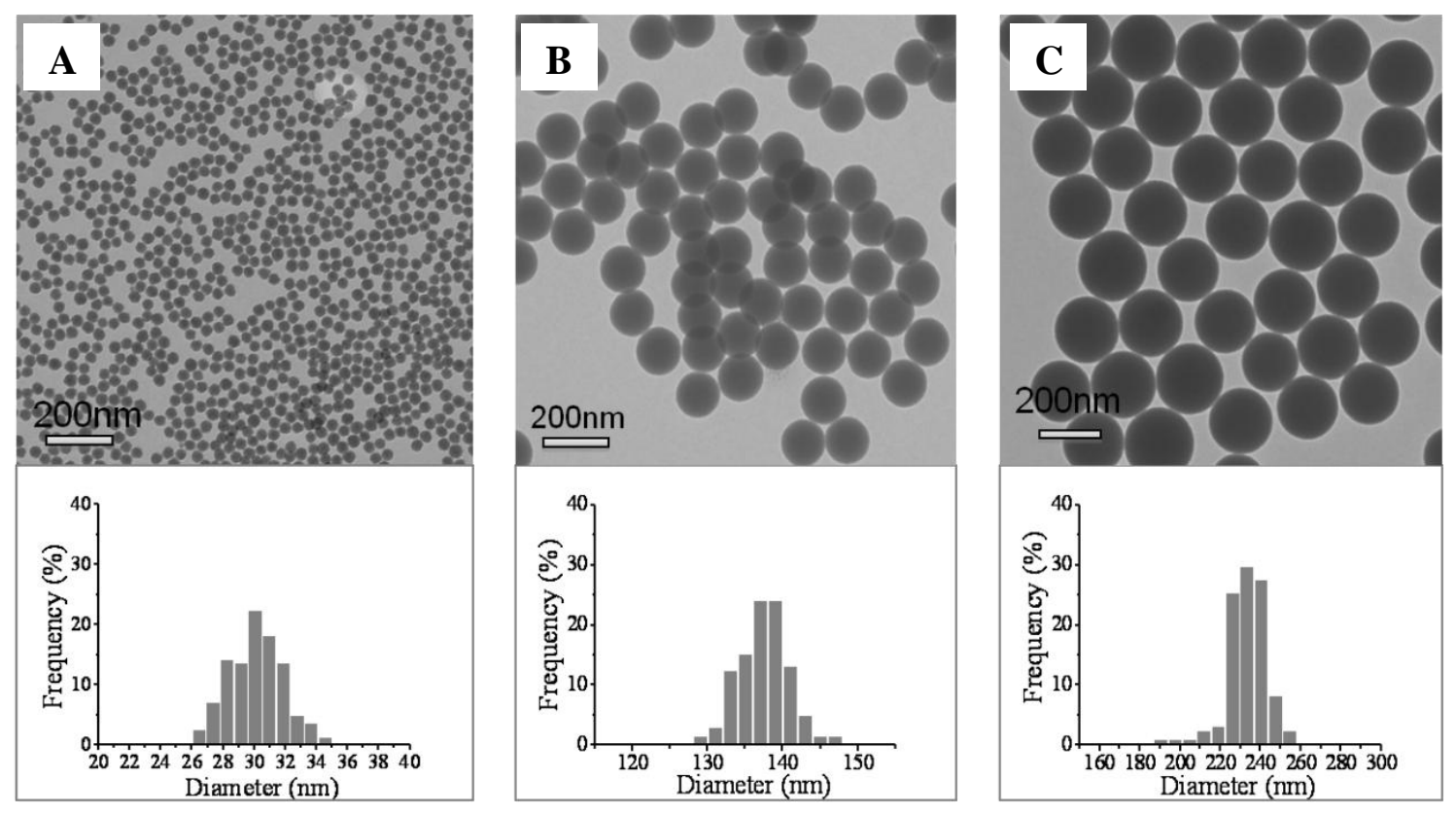

Figure 1. TEM images and size histograms of the silica particles used in this work. (A) $D_{\mathrm{n}}=$ $30 \mathrm{~nm}, D_{\mathrm{w}} / D_{\mathrm{n}}=1.01 ;(\mathrm{B}) D_{\mathrm{n}}=136 \mathrm{~nm}, D_{\mathrm{w}} / D_{\mathrm{n}}=1.01$ and $(\mathrm{C}) D_{\mathrm{n}}=230 \mathrm{~nm}, D_{\mathrm{w}} / D_{\mathrm{n}}=1.01$ 
Synthesis of PEOMA-based brush-type macroinitiator. The brush-type PEOMA-based macroalkoxyamine initiator $\left(\mathrm{P}\left[\left(\mathrm{PEOMA}_{950}\right)_{12}-c o-\mathrm{S}_{1}\right]-\mathrm{SG} 1, M_{\mathrm{n}}=11700 \mathrm{~g} \mathrm{~mol}^{-1}\right.$ and $M_{\mathrm{w}} / M_{\mathrm{n}}=$ 1.11) was synthesized following a previously reported procedure. ${ }^{24}$ In a typical experiment, the monomers (PEOMA and S), SG1 and ethanol were introduced in an Erlenmeyer flask and the mixture was deoxygenated under nitrogen for $20 \mathrm{~min}$ at room temperature. The BlocBuilder $^{\circledR}$ alkoxyamine initiator was then added to the solution and nitrogen bubbling was carried out for $10 \mathrm{~min}$. The mixture was then transferred into a three-neck round-bottom flask $(500 \mathrm{~mL})$ immersed in an oil bath, and heated at $78.5^{\circ} \mathrm{C}$. The reaction was conducted for $2 \mathrm{~h}$ and the final product was precipitated in diethyl ether and dried under vacuum before analysis.

\section{Emulsion copolymerization of BMA and $S$ in the presence of macroalkoxyamine-} adsorbed silica particles. The emulsion copolymerization of BMA with a small percentage of styrene was carried out at $85^{\circ} \mathrm{C}$. Typically (entry EH01 in Table 1), a known quantity of macroinitiator $(0.46 \mathrm{~g} ; 2.4 \mathrm{mM})$ was dissolved in $25 \mathrm{~g}$ of water mixed with $136 \mathrm{~nm}$ diameter silica particles $\left(50 \mathrm{~g} \mathrm{~L}^{-1}\right)$. The $\mathrm{pH}$ was adjusted to 2.2 by the addition of a few drops of hydrochloric acid ( $0.1 \mathrm{M}$ aqueous solution). The resulting suspension was then stirred with a magnetic stirrer $(200 \mathrm{rpm})$ at room temperature for 30 min under nitrogen atmosphere. BMA and $\mathrm{S}$ (2.35 $\mathrm{g}$ of BMA and $0.15 \mathrm{~g}$ of $\mathrm{S}$ ), were then added and the obtained unstable biphasic system was deoxygenated by nitrogen bubbling for another $20 \mathrm{~min}$. This mixture was introduced into a $50 \mathrm{~mL}$ round flask, and heated at $85{ }^{\circ} \mathrm{C}$ for $6 \mathrm{~h}$ while stirring at $200 \mathrm{rpm}$ still with the aid of a magnetic stirrer. Time zero of the polymerization was taken when the reaction temperature reached $70{ }^{\circ} \mathrm{C}$. Samples were periodically withdrawn to follow monomer conversion by gravimetric analysis. Sodium hydroxide (0.1 M aqueous solution) was used to control the $\mathrm{pH}$ value of experiments performed at $\mathrm{pH}$ around 8 (EH05 and EH08, Table 1) before addition of monomer. 
Table 1. Summary of experimental conditions and results for the surfactant-free synthesis of silica/polymer nanocomposite latex particles by emulsion copolymerization of BMA and $\mathrm{S}(8 \mathrm{~mol} \%)$ at $85{ }^{\circ} \mathrm{C}$ using the $\mathrm{P}\left[\left(\mathrm{PEOMA}{ }_{950}\right)_{12}-\mathrm{co}-\mathrm{S}_{1}\right]-\mathrm{SG} 1$ copolymer as macroinitiator for different silica particle sizes and different $\mathrm{pH}$ values. ${ }^{\mathrm{a}}$

\begin{tabular}{|c|c|c|c|c|c|c|c|c|c|c|c|}
\hline Entry & $\begin{array}{c}D_{\mathrm{n}} \text { Silica } \\
(\mathbf{n m})^{b}\end{array}$ & $\begin{array}{c}\text { [Silica] } \\
\left(\mathrm{g} \mathrm{L}^{-1}\right)\end{array}$ & $\mathbf{p} \mathbf{H}^{\mathbf{c}}$ & 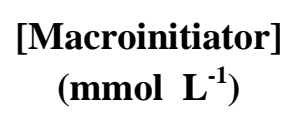 & $\begin{array}{l}\text { Target } M_{\mathrm{n}} \\
\left(\mathrm{g} \mathrm{mol}^{-1}\right)^{d}\end{array}$ & $\begin{array}{l}\text { Conv. } \\
(\%)^{e}\end{array}$ & $\begin{array}{l}M_{\mathrm{n}}\left(M_{\mathrm{w}} / M_{\mathrm{n}}\right)^{\mathrm{f}} \\
\quad\left(\mathrm{g} \mathrm{mol}^{-1}\right)\end{array}$ & $\begin{array}{c}\mathbf{Z}_{\text {av }}(\mathbf{D L S}) \\
(\mathbf{n m})\end{array}$ & $\begin{array}{c}\text { Poly } \\
\text { (DLS) }\end{array}$ & $\begin{array}{c}D_{\mathrm{n}}(\mathrm{TEM}) \\
(\mathbf{n m})^{\mathrm{g}}\end{array}$ & $\begin{array}{r}D_{\mathrm{w}} / D_{\mathrm{n}} \\
(\mathrm{TEM})\end{array}$ \\
\hline EH01 & 136 & 50 & $2.2(+)$ & 2.4 & 79266 & 53.4 & $58300(1.9)$ & 232 & 0.55 & 80 & 1.03 \\
\hline EH02 & 136 & 50 & $5.8(+)$ & 2.4 & 80015 & 52.8 & $57300(1.8)$ & 218 & 0.57 & 86 & 1.03 \\
\hline EH03 & 136 & 50 & $6.7(+)$ & 2.4 & 80513 & 74.9 & $56900(2.3)$ & 636 & 0.28 & / & / \\
\hline ЕH04 & 136 & 50 & 7.7 & 2.1 & 90229 & 80.3 & $51300(2.2)$ & 651 & 0.28 & / & / \\
\hline ЕH06 & 30 & 25 & $8.0(-)$ & 2.4 & 78241 & 69.7 & $60300(1.8)$ & 1020 & 0.50 & / & / \\
\hline ЕH07 & $30^{\mathrm{h}}$ & 25 & $5.2(+)$ & 2.4 & 79730 & 72.1 & $47600(1.8)$ & 166 & 0.04 & / & / \\
\hline ЕH08 & $30^{\mathrm{h}}$ & 25 & $8.1(-)$ & 2.4 & 79600 & 63.5 & $47600(1.1)$ & 206 & 0.12 & / & / \\
\hline
\end{tabular}

${ }^{\mathrm{a}}$ Total monomer concentration $=20 \mathrm{wt} \%$ and reaction time $=6 \mathrm{~h}$.

${ }^{\mathrm{b}}$ Determined by TEM. ${ }^{\mathrm{c}}$ Initial $\mathrm{pH}$ determined before polymerization, natural or adjusted with $\mathrm{HCl}(+)$ or $\mathrm{NaOH}(-)$. ${ }^{\mathrm{d}}$ Theoretical molar mass at $100 \%$ conversion determined according to: Target $M_{\mathrm{n}}=M_{\mathrm{n}}$ (macroinitiator) $+M_{\mathrm{n}}$ (macroinitiator) x (initial mass of monomer/mass of macroinitiator). ${ }^{\mathrm{e}}$ Determined by gravimetric analysis. ${ }^{\mathrm{f}}$ Determined by SEC in THF using PMMA standards. ${ }^{\mathrm{g}}$ Diameter of latex particles in the TEM images. ${ }^{\mathrm{h}} \gamma$-MPS-functionalized silica particles 
Characterizations. The composition of the macroalkoxyamine initiator was determined by ${ }^{1}$ H NMR spectroscopy (Bruker DRX 300) by the integration of the vinyl protons of the monomers using 1,3,5-trioxane as an internal reference (three vinyl protons for styrene at $\delta=$ $6.74 \mathrm{ppm}, 5.83 \mathrm{ppm}$ and $5.25 \mathrm{ppm}$, and two $\mathrm{CH}_{2}$ protons for PEOMA at $\delta=6.04 \mathrm{ppm}$ and $5.69 \mathrm{ppm}){ }^{24}$ Size exclusion chromatography (SEC) analyses were performed in THF at 40 ${ }^{\circ} \mathrm{C}$ for both the macroalkoxyamine initiator and the diblock copolymers obtained in the emulsion polymerization experiments. The flow rate of the mobile phase was $1 \mathrm{~mL} \mathrm{~min}^{-1}$ and toluene was used as a flow rate maker. The samples were injected at a concentration of $3 \mathrm{mg}$ $\mathrm{mL}^{-1}$ after filtration through a $0.45 \mu \mathrm{m}$ pore-size membrane. The separation was carried out on three Polymer Laboratories columns [3 $\times$ PLgel $5 \mu \mathrm{m}$ Mixed C $(300 \times 7.5 \mathrm{~mm})]$ and a guard column (PL gel $5 \mu \mathrm{m}$ ). A calibration curve based on PMMA standards was used to calculate the average molar masses and molar mass dispersities. Samples synthesized in the presence of silica were first dried at room temperature for 2 days, and then diluted in THF (HPLC grade) under stirring. The solution was then centrifuged at $21000 \mathrm{rpm}$ for $1 \mathrm{~h}$ to remove the silica particles before injection. The grafting density of the silane molecule was determined by thermogravimetric analysis (TGA) on a TGA Q50 from TA Instrument using a temperature ramp from 20 to $800{ }^{\circ} \mathrm{C}$ at a heating rate of $10{ }^{\circ} \mathrm{C} \mathrm{min}^{-1}$. The particle size (average hydrodynamic diameter, $\mathrm{Z}_{\mathrm{av}}$ ) was measured by dynamic light scattering (DLS) using the Nano ZS instrument from Malvern. The data were collected at $173^{\circ}$ scattering angle using the fully automatic mode of the Zetasizer system. The broadness of the distribution was given by a dimensionless number called poly value determined from the autocorrelation function using the second-order method of cumulant analysis (the higher this value, the broader the size distribution). Before analysis, the samples were diluted in deionized water and the reported particle size represents an average of at least 3 measurements. 
The silica particles were imaged by transmission electron microscopy (TEM) with a Philips CM120 transmission electron microscope operating at an accelerating voltage of 80 $\mathrm{kV}$ (Centre Technologique des Microstructures, plate-forme de l’Université Claude Bernard, Lyon 1, Villeurbanne, France). Highly diluted samples were dropped on a formvar-carbon coated copper grid and dried under air. To prevent particle deformation (the P(BMA-co-S) hydrophobic block constituting the core of the latex particles has a glass transition temperature, $\mathrm{T}_{\mathrm{g}}$, close to the ambient), and allow reliable determination of particle size and morphology, the composite latex particles were characterized by cryo-transmission electron microscopy (cryo-TEM). The diluted samples were dropped onto 300 Mesh holey carbon films (Quantifoil R2/1) and quench-frozen in liquid ethane using a cryo-plunge workstation (made at LPS Orsay). The specimens were then mounted on a precooled Gatan 626 specimen holder, transferred in the microscope (Phillips CM120) and observed at an accelerating voltage of $120 \mathrm{kV}$. The number-average $\left(D_{\mathrm{n}}\right)$ and the weight-average $\left(D_{\mathrm{w}}\right)$ diameters of the silica particles and of the polymer nodules formed at the silica surface were determined directly on the TEM micrographs according to: $D_{\mathrm{n}}=\Sigma \mathrm{n}_{\mathrm{i}} D_{\mathrm{i}} / \Sigma \mathrm{n}_{\mathrm{i}}$ and $D_{\mathrm{w}}=\Sigma \mathrm{n}_{\mathrm{i}} D_{\mathrm{i}}{ }^{4} / \Sigma \mathrm{n}_{\mathrm{i}} D_{\mathrm{i}}{ }^{3}$, where $\mathrm{n}_{\mathrm{i}}$ is the number of particles with diameter $D_{\mathrm{i}}$. A minimum of 150 particles was counted for each batch.

Cryo-electron tomography (cryo-ET) experiments were performed on a Tecnai F20 FEG operating at 200kV using a Gatan 626 specimen holder (Chimie et Biologie des Membranes et des Nanoobjets, UMR 5248, Bordeaux, France). Automatic acquisition of tilt-series from $60^{\circ}$ to $+60^{\circ}$ at $2^{\circ}$ intervals along the tilt axis was performed using the FEI tomography software. The defocus was $\sim 10 \mu \mathrm{m}$, and the pixel size corresponded to $1.08 \mathrm{~nm}$ at the specimen level. For tilt-series alignment, the images were binned 2-fold and were aligned with the IMOD software package images, ${ }^{28}$ using gold particles as fiducial markers. The 
tomographic reconstructions were calculated by weighted back-projection using Priism package. $^{29}$

\section{RESULTS AND DISCUSSION}

As shown previously, ${ }^{15}$ surfactant-free emulsion copolymerization of BMA with styrene initiated by $\mathrm{P}\left[\left(\mathrm{PEOMA}_{950}\right)_{12}-\mathrm{Co}_{-} \mathrm{S}_{1}\right]-\mathrm{SG} 1$ in the presence of silica particles in acidic conditions $(\mathrm{pH}<6.0)$ allows the formation of a variety of composite particles. The morphology evolved from dumbbell- to daisy-, and then raspberry-like by varying the experimental conditions, and in particular the macroalkoxyamine initiator concentration.

In the present study, we were further interested in exploring the effect of $\mathrm{pH}$ on the morphology of the self-assembled structures while varying simultaneously the silica particle size. Indeed, numerous studies $3,9,30,31$ have shown that this last parameter has a strong influence on the morphology of composite particles synthesized by emulsion polymerization irrespective of the synthetic strategy used. Furthermore, one might expect that a change in $\mathrm{pH}$ will favor the formation of non-spherical morphologies leading to new silica/BCP assemblies.

Effect of pH. In a first set of experiments, the $136 \mathrm{~nm}$ diameter silica particles (Figure 1) were used to investigate the effect of the $\mathrm{pH}$ (and indirectly of the ionic strength) on the polymerization kinetics and particle morphology. It should be noted here that the natural $\mathrm{pH}$ of the silica suspension $\left([\right.$ Silica $\left.]=50 \mathrm{~g} \mathrm{~L}^{-1}\right)$ containing the macroinitiator $(2.4 \mathrm{mM})$ was approximately 8.0. The $\mathrm{pH}$ was reduced to 7.7, 6.7, 5.8 and finally 2.2 (samples EH04, EH03, EHO2 and EH01, respectively, Table 1) through the addition of hydrochloric acid, which obviously resulted in an increase of ionic strength. As shown in Figure 2, the conversion 
versus time curves can be divided into two groups depending on $\mathrm{pH}$. The polymerization rate decreased with decreasing pH from 7.7 (EH04) or 6.7 (EH03) to 5.8 (EH02) or 2.2 (EH01).

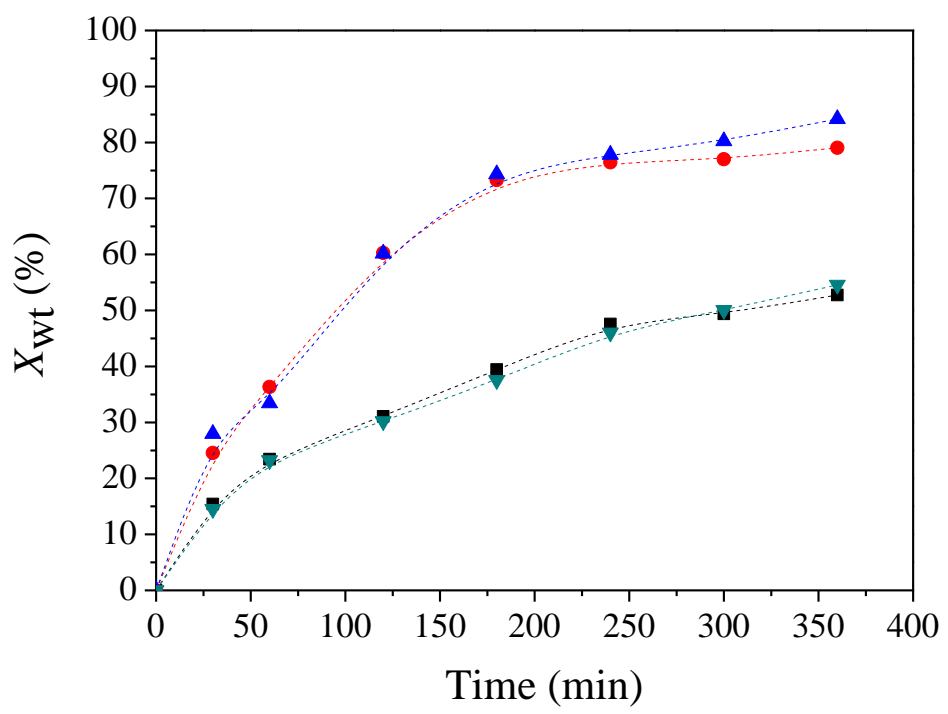

Figure 2. Conversion versus time curves for surfactant-free emulsion copolymerization of BMA and $\mathrm{S}$ performed in the presence of $136 \mathrm{~nm}$ diameter silica particles using $\mathrm{P}\left[\left(\mathrm{PEOMA}_{950}\right)_{12}-c o-\mathrm{S}_{1}\right]-\mathrm{SG} 1$ as macroinitiator $\left(2.4 \mathrm{mmol} \mathrm{L}^{-1}\right)$ for different $\mathrm{pH}$ values: $\mathrm{EH} 01$ $(\mathrm{pH}=2.2, \nabla), \mathrm{EH} 02(\mathrm{pH}=5.8, \mathbf{\square}), \mathrm{EH} 03(\mathrm{pH}=6.7, \bullet)$ and EH04 $(\mathrm{pH}=7.7, \boldsymbol{\Delta})($ Table 1).

According to the literature, SG1 degrades under acidic conditions. This should result therefore in a decrease of the free SG1 concentration, and hence in higher reaction rates. ${ }^{24}$ The fact that the reaction rate actually decreases is thus likely due to the concomitant increase of ionic strength as previously observed for polymerizations performed in the absence of silica. $^{24}$ These two opposing effects (increase in rate with decreasing $\mathrm{pH}$ and decrease in rate due to a higher ionic strength) incidentally resulted in two overlapping pairs of plots (EH04/EH03 and EH02/EH01, respectively). Also, an effect of the silica particle surface on kinetics (which would be pH-dependent) cannot be completely ruled out. However, an indepth discussion of such effect is beyond the scope of this paper. Besides, SEC analysis (Figure S1 in the Supporting Information) showed the successful formation of block 
copolymers regardless of the $\mathrm{pH}$ value, as attested by the shift of the SEC traces towards higher molar masses, with however a small proportion of dead chains. These results are similar to the ones reported in our earlier work in the absence of silica ${ }^{24}$ suggesting a similar level of control.

Figure 3 shows cryo-TEM images of the hybrid particles synthesized at low $\mathrm{pH}(\mathrm{pH}=2.2$ and 5.8, respectively). As described earlier, ${ }^{15}$ multipod-like hybrids were observed under these conditions despite the fact that the ionic strength increased with decreasing $\mathrm{pH}$, which should promote the formation of vesicles and/or worm-like micelles. ${ }^{24}$ This suggests that the presence of the inorganic particles is responsible for the deviation from the typical selfassembly of block copolymers. Indeed, in the presence of silica, multipod-like particles are likely formed in the early steps of the PISA process (i.e. at very low monomer conversions) by self-assembly of BCP amphiphilic species generated both in water and at the silica surface. ${ }^{15}$ Under conventional circumstances, without inorganic particles, the self-assembled BCPs should aggregate together to form vesicles or polymer worms at higher monomer conversion. However, macroinitiator adsorption on the silica surface may stabilize the assembly and retard the onset at which such morphology transition would occur. The

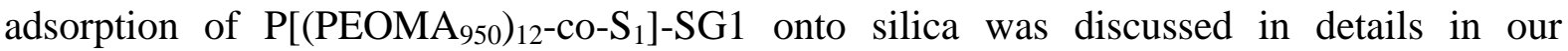
previous paper. ${ }^{15}$ It was suggested that the macroinitiator adopts a flat configuration on the silica surface to maximize the interaction between the ether oxygen of the ethylene oxide units and the acidic silanol groups through hydrogen bonding. According to this scenario, a decrease in $\mathrm{pH}$ should promote adsorption as the number of binding site should increase. This may contribute to decreasing molecular mobility at the silica/polymer interface, which would further stabilize the assembled block copolymers and prevent any morphological evolution.

When the $\mathrm{pH}$ was increased to 6.7, snowman-like vesicles (with the silica particles composing the head, and the vesicles the body) were mainly observed (Figures 3C and 3D). 

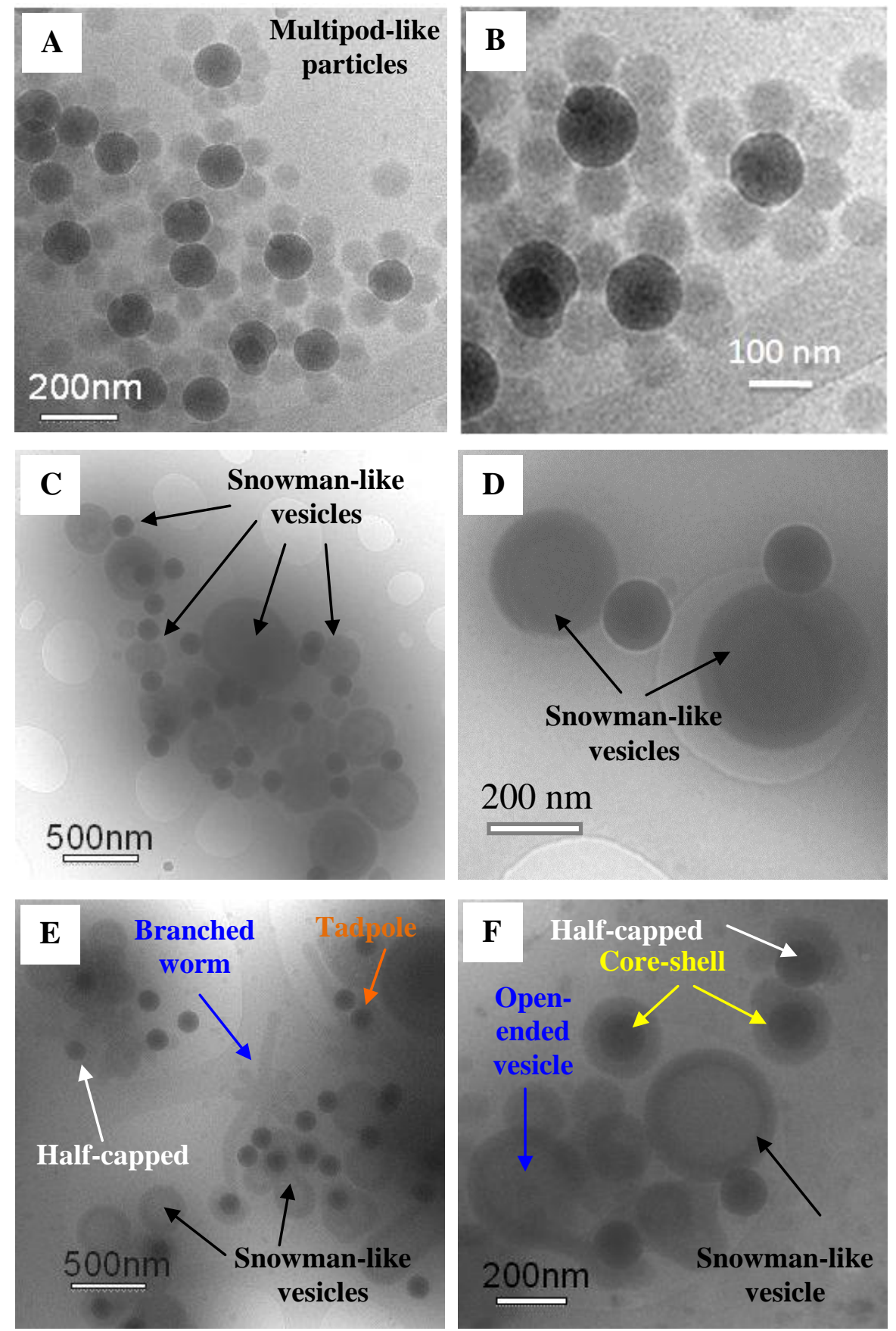

Figure 3. Cryo-TEM images of silica/polymer composite particles obtained by nitroxidemediated surfactant-free emulsion copolymerization of BMA and $\mathrm{S}$ carried out in the presence of $136 \mathrm{~nm}$ diameter silica particles for different $\mathrm{pH}$ values. (A) $\mathrm{pH}=2.2$, (B) $\mathrm{pH}=$ 5.8, $(\mathrm{C}, \mathrm{D}) \mathrm{pH}=6.7$ and $(\mathrm{E}, \mathrm{F}) \mathrm{pH}=7.7(\mathrm{EH} 01$ to EH04 in Table 1). The arrows point to half-capped (white), core-shell (yellow), tadpole- (orange) and snowman-like vesicle (black) morphologies, respectively. Intermediate structures such as a branched worm and an openended vesicle (indicated by blue arrows in Figures 3E and 3F) can also be seen. 
As far as we know, this is the first example of vesicle self-assembly at the surface of inorganic particles. These vesicular structures likely originate from the fusion of the polymer nodules formed at the silica surface in the early stages of polymerization into short worms, which evolved into longer worms and finally vesicles upon increasing monomer to polymer conversions as schematically represented below (Scheme 1). We will return to the mechanism of vesicle formation later in the discussion. Note that such vesicular morphologies were previously observed at lower $\mathrm{pH}$ in the absence of silica $(\mathrm{pH}=6.0)$, which again suggests that the latter contributes to retard their appearance. Worm-like micelles indeed constituted the primary morphology at $\mathrm{pH}=6.7$ in the absence of silica.

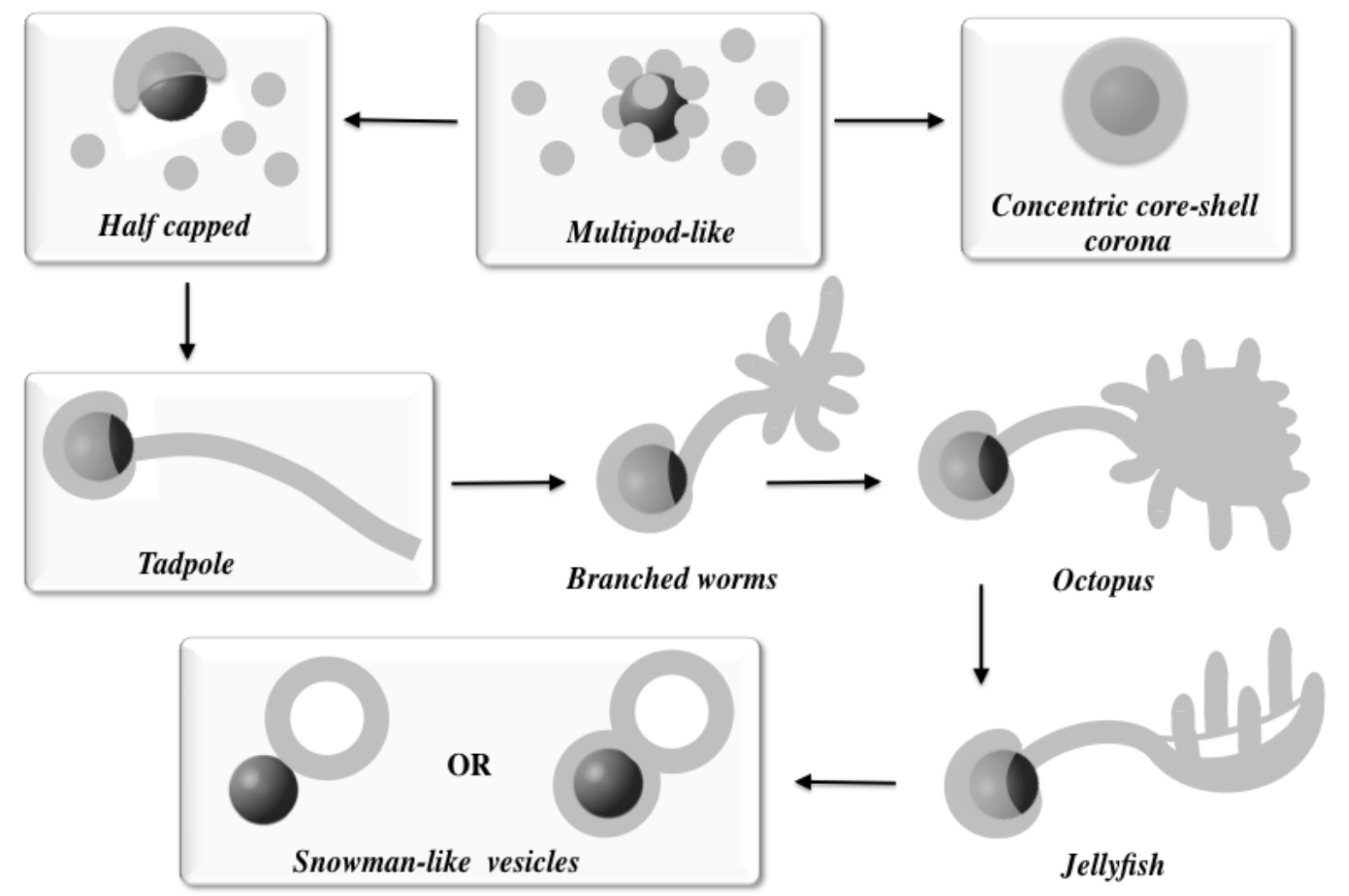

Scheme 1. Suggested mechanism of formation of half-capped, core-shell, tadpole and snowman-like vesicle morphologies during nitroxide-mediated polymerization induced selfassembly of BCPs at the surface of $136 \mathrm{~nm}$ diameter silica particles at $\mathrm{pH}$ 7.7. 
A further increase in $\mathrm{pH}$ from 6.7 to 7.7 resulted in a complex mixture of kineticallytrapped copolymer morphologies (Figures 3E and 3F). Cryo-TEM images showed the coexistence of three intrinsically different nano-objects: i) silica particles encapsulated by polymer with a regular core-shell structure (indicated by yellow arrows in Figure 3F), ii) silica particles "half-capped" by a polymer shell (white arrows in Figure 3E and 3F), and iii) snowman-like geometry, with silica (or encapsulated silica) particles bound to polymer vesicles (black arrows in Figure 3F). As worm-like micelles were the predominant nanoparticle morphology formed around $\mathrm{pH} 7$ in the absence of silica, we suspect that the core-shell particles result from the fusion of the polymer nodules formed at the silica surface with neighboring nodules in a process similar to the formation of polymer worms in solution except that it is taking place at the inorganic particle surface, leading to the formation of a hemi-cap or of a complete shell. As they are growing, the polymer nodules may also undergo fusion with free latex particles formed in solution, leading to a tadpole-like morphology characterized by a silica or hemi-capped silica particle from which a worm-like micelle is extending (indicated by an orange arrow in Figure 3E) (Scheme 1).

The formation of the vesicular morphology can also be understood as an extension from previous work, ${ }^{32}$ where polymer worms originate from the gradual evolution of spheres into dimers and trimers that evolve further to linear fibers and finally vesicles. The fact that both protruding polymer worms (i.e. polymer fibers extending from the inorganic particles in a tadpole-like morphology) and snowman-like vesicles are observed in Figures 3E and 3F seem to indicate that a similar phase rearrangement is taking place at the silica surface at $\mathrm{pH} 7.7$. Armes et $a .^{32}$ proposed a mechanism for the worm-to-vesicle transformation during the synthesis of poly(glycerol monomethacrylate)-b-poly(2-hydroxypropyl methacrylate) (PGMA- $b$-PHPMA) diblock copolymers by RAFT-mediated aqueous dispersion 
polymerization. Careful monitoring of the HPMA polymerization by TEM revealed a variety of intermediate morphologies like branched worms, bilayer octopi- or jellyfish-like structures. ${ }^{32}$ Branching worms led to the formation of polymer tentacles that further wrappedup into jellyfish. The jellyfish structure was shown to be the final stage prior to vesicle formation: the jellyfish "tentacles" underwent fusion to form predominantly a vesicular phase. Such an intermediate branched worm structure is clearly visible on Figure 3E while an open-ended nascent vesicle morphology can be observed in Figure 3F (indicated by blue arrows).

According to these observations, we hypothesize that polymer worms are first grown at the silica surface via the fusion of polymer nodules with freestanding latex particles in solution to form a tadpole-like structure comprised of a silica (or encapsulated silica) particle head and a polymer tail. The polymer tail would then undergo branching and partial coalescence to give an octopus morphology connected to one or several silica particles via its tentacles. Further wrapping and coalescence of the polymer tentacles would then result in a jellyfish structure originating from incomplete worm and/or bilayer fusion, and then finally completely wrap to form a vesicle (Scheme 1).

Further evidence for tadpole-, half-capped, core-shell-corona and vesicular-like structures is given in Figure 4. Figure 4C shows an enlarged view of the tadpole- and core-shell particles. Remarkably, the brush-like surface of the latex (i.e. the corona) can be clearly observed (indicated by black arrows). A rough estimate of the corona thickness gives a brush layer of around $10 \mathrm{~nm}$, which is consistent with the length of two PEO side chains from the comb-like macroalkoxyamine (i.e. approximately $2 \times 6 \mathrm{~nm}$ ). A thin sharp white contour (indicated by a red arrow) is also clearly visible at the polymer/silica interface. This could correspond to entrapped macroinitiator, however it is more likely due to an artifact resulting from fringes appearing at high defocus values chosen for enhancing image contrast. 


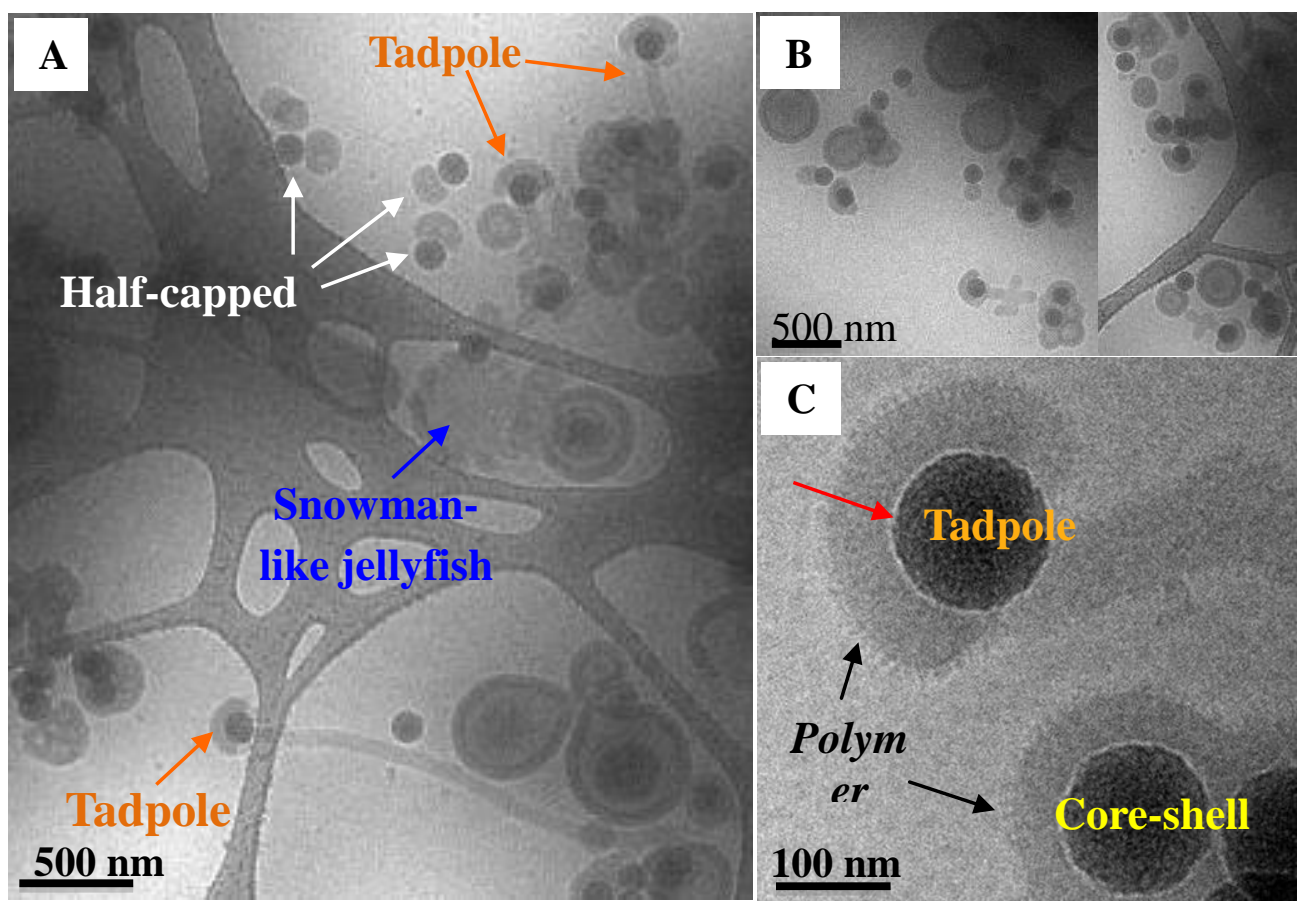

Figure 4. Typical low (A, B) and high (C) magnification cryo-TEM images of silica/polymer composite latex particles obtained by emulsion copolymerization of BMA and S using $\mathrm{P}\left[\left(\mathrm{PEOMA}_{950}\right)_{12}-c o-\mathrm{S}_{1}\right]-\mathrm{SG} 1$ as macroinitiator $\left(2.1 \mathrm{mmol} \mathrm{L}^{-1}\right)$ in the presence of $136 \mathrm{~nm}$ diameter silica particles at pH 7.7 (entry EH04, Table 1). The black and red arrows point to the polymer brush and to the silica/polymer interface, respectively.

We have managed to capture an image of a partially wrapped octopus/jellyfish (blue arrow in Figure 4A), which is what we consider to be the final transitional structure towards the formation of a vesicle. Since the silica particle remains attached, the final nanohybrid structure resembles a snowman, with the silica (or encapsulated silica) particle forming the head and the vesicle forming the body. Interestingly, the thickness of the snowman-like vesicle bilayer is very close to the shell thickness of the core-shell or hemi-capped particles, supporting the assumption that all three self-assembled structures originate from the fusion of the polymer nodules formed at the silica surface. Further evidence of such worm-to-vesicle transition is provided in the following section. 
Cryo-electron tomography (cryo-ET) analyses. Cryo-ET was used to gain a deeper insight into the complex structures of the polymer/silica hybrid particles shown in Figures 3 and 4. Cryo-ET is a method of choice for 3D imaging of single objects. This technique consists in the acquisition of a series of cryo-TEM images of a single object viewed at different angles relative to the electron beam and the 3D reconstruction. In materials science, this approach has been developed for the study of mesoporous materials, ${ }^{33,34,35,36}$ nanocomposite particles, ${ }^{37}$ carbon nanotubes,${ }^{38}$ dispersions of silica particles into natural rubber, ${ }^{39}$ and self-assembled aggregates. ${ }^{40}$ Two main types of morphologies were selected for cryo-ET analysis to directly confirm their structure: i) the regular core-shell-corona particles (which contains in this particular example two silica beads), and an intermediate branched worm structure protruding from the silica particle surface (Figures 5 and 6, respectively). Figure 5 shows the results for the double-core-shell particles.
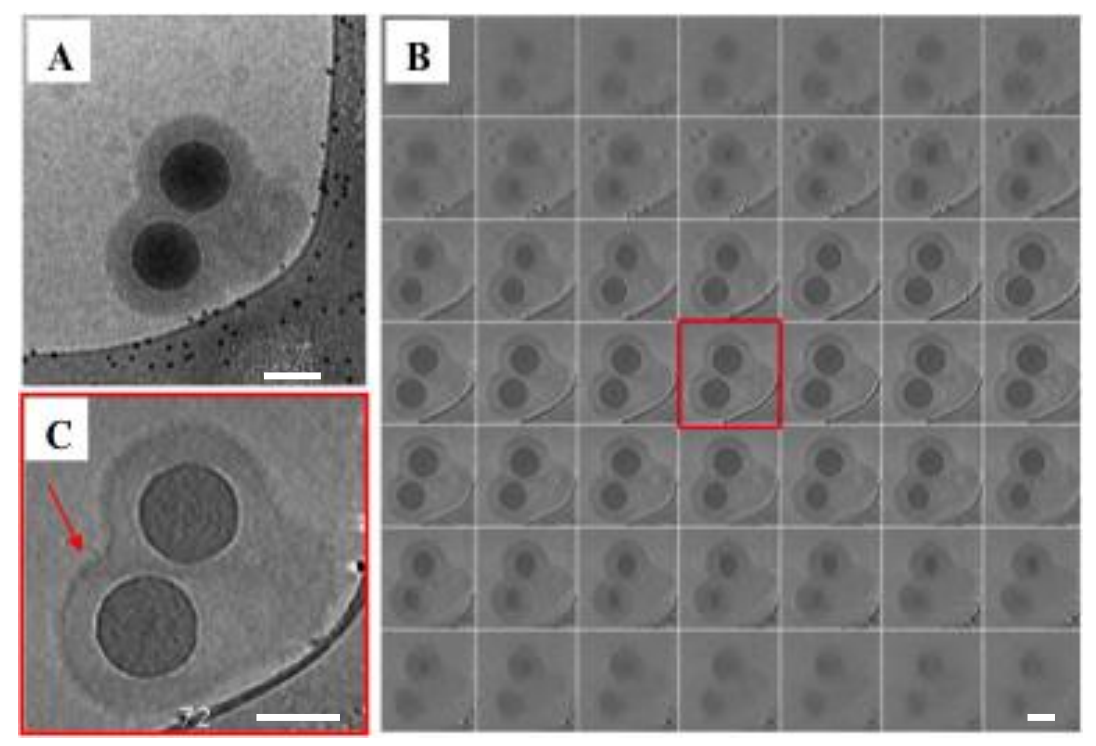

Figure 5. Cryo-ET analysis of concentric double-core-shell-corona hybrid particles (EH04). (A) Cryo-TEM image showing the nano-object that has been selected for the reconstruction map. (B) Series of $\mathrm{z}$ slices of the tomogram from the particle selected in image A showing complete silica encapsulation. (C) Selected image of the red square in image B. The red arrow points to the polymer brush. Scale bar: $100 \mathrm{~nm}$. 
The particles shown in Figure 5A were selected for the cryo-ET experiment. Analysis of the $\mathrm{x}-\mathrm{y}$ sections (Figure 5B) shows that the silica particles (dark in the images) are fully covered by polymer (grey in the images). The $\mathrm{z}$ slices of the reconstruction also show the brush-like surface (red arrow in Figure 5C) of the polymer. The polymer shell is clearly visible from the top to the bottom of the silica nanoparticles suggesting that the latter are fully encapsulated.

Figure 6A shows the cryo-TEM image of an intermediate partially coalesced branched worm structure (particle $\mathrm{N}^{\circ} 1$ highlighted by the blue rectangle), previously denominated as an octopus structure in the literature. Interestingly, the octopus structure is connected to the silica particle by one of its tentacle providing further evidence that $\mathrm{BCP}$ self-assembly is occurring at the silica surface. Inspection of the cross-sections (Figure 6B) reveals that the silica particle (which appears as bright) is again fully encapsulated by polymer (light grey in the images). To gain further insight into particle morphology, segmentation was used to generate graphical representations demonstrating the remarkable 3D structure of the particles (Figure 6C), which was not observable from the $\mathrm{x}-\mathrm{y}$ sections of the 3D volume only (Figure $6 \mathrm{~B})$. The visualization of the segmented volume was observed from three directions in Figure 6C. The structure of the protruding tentacle (green arrow) connecting the encapsulated silica with the nascent bilayer vesicle (red arrows) and the brush-like surface (orange arrows) of the polymer can be clearly seen in these 3D images. This cryo-ET analysis also remarkably shows the wrapping-up of the octopus tentacles (white arrow) to form the jellyfish that will evolve further into a vesicle. As mentioned above, this jellyfish nanostructure was already shown to be a key intermediate during the polymerization-induced worm-to-vesicle transition during the synthesis of self-assembled copolymers by RAFT dispersion polymerization. ${ }^{32}$ However, this is to our knowledge the first report describing the formation of such morphologies using NMP, furthermore in the presence of inorganic particles. Such a transient 
morphology is difficult to be confirmed with cryo-TEM only. The present article thus highlights the benefits of advanced techniques like cryo-ET for more accurate characterization of particles with complex shapes such as the ones reported in this work.
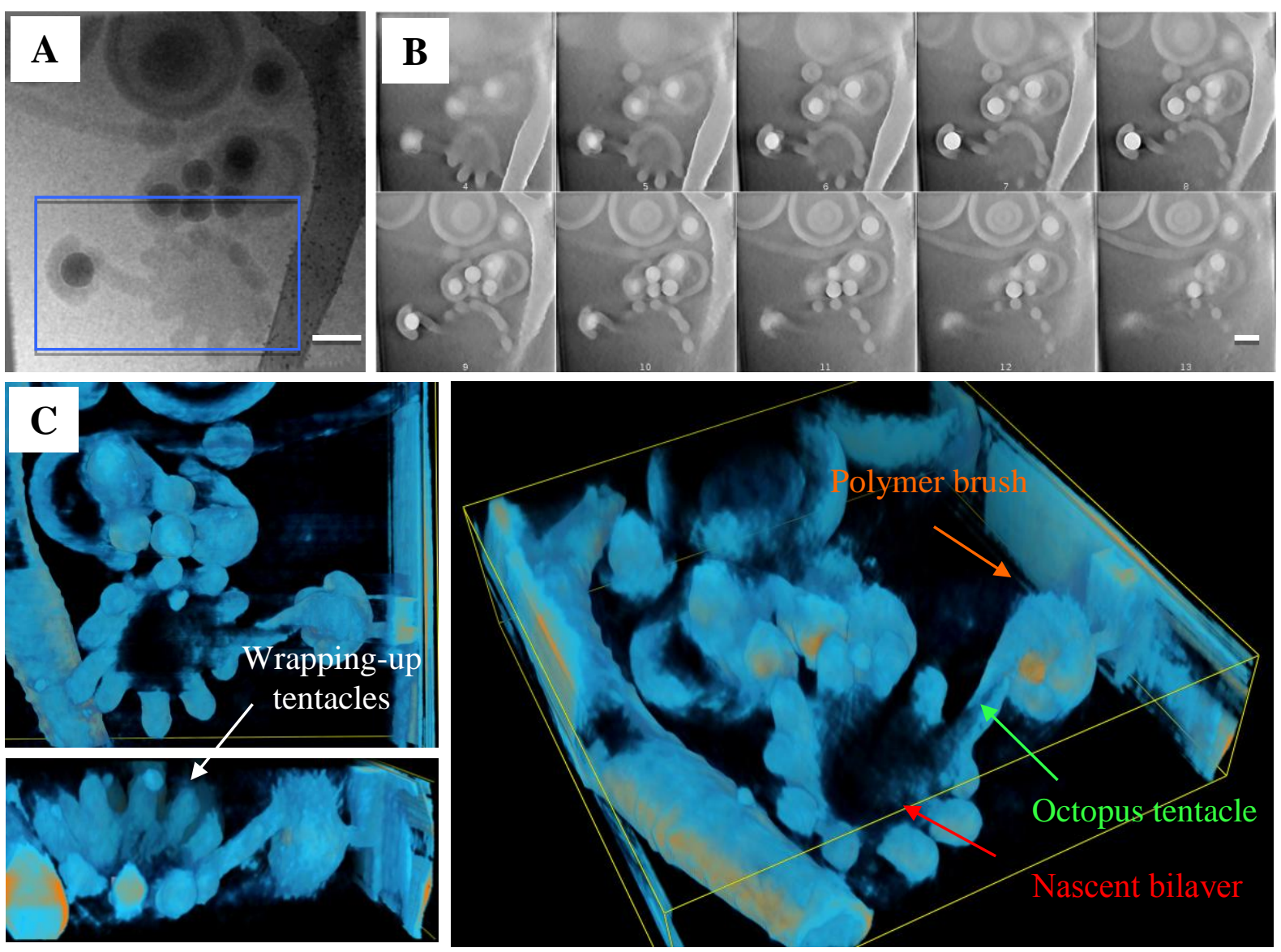

Figure 6. Cryo-ET analysis of an intermediate branched worm structure with protruding tentacles (EH04). (A) Cryo-TEM image of the selected particle. (B) Selected z-slices of a volume reconstructed from image A. (C) Isosurface of the tomogram rendered in top, $45^{\circ}$ and from views, respectively. Scale bar: $200 \mathrm{~nm}$.

Finally, although this was not the predominant morphology at high $\mathrm{pH}$ values, the snowman-like composite particles shown in Figure 7A were also characterized by cryo-ET. 
Figure 7B shows a series of cryo-TEM images at different tilt angles. Again, the polymer brush is clearly visible at the particle surface. Surprisingly, the polymer nodule (indicated by red arrows) does not appear spherical but as an oblate spheroid. There are several possible explanations; however further work is necessary to verify our observations before extrapolating to a conclusion.

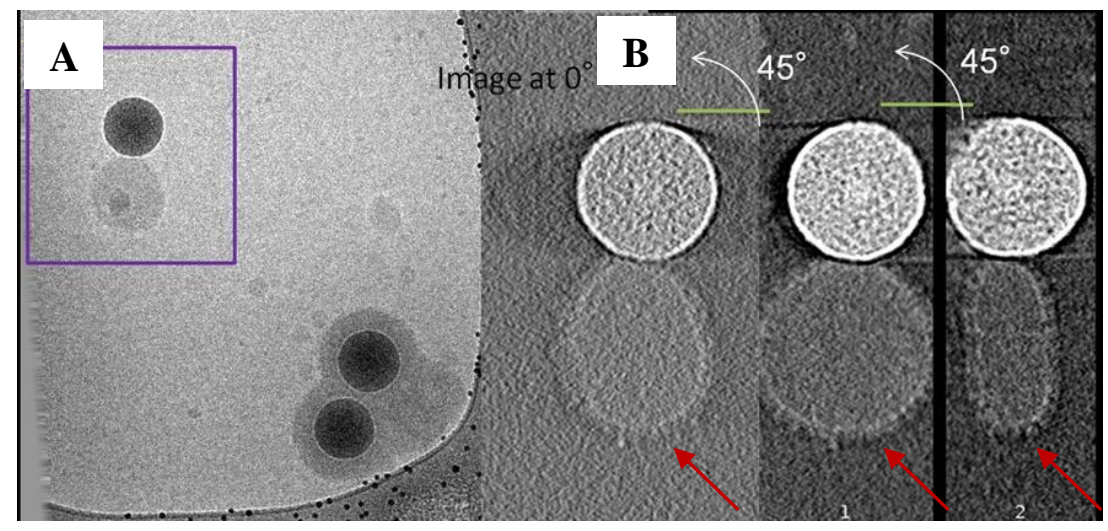

Figure 7. (A) Cryo-TEM image of a snowman-like composite particle (EH04 in Table 1) and (B) Gallery of the selected particle observed at different tilt angles.

Effect of silica particle size. Compared to conventional PISA of BCPs, the inclusion of silica by a route that promotes polymer formation at its surface led to very different morphologies depending on the suspension $\mathrm{pH}$. Therefore, given the importance of silica on morphology, we then varied the size of the silica particles under basic conditions in order to see its effect on the self-assembly. An experiment was first conducted using the $230 \mathrm{~nm}$ diameter silica particles at pH 8.2 (EH05, Table 1). As shown in Figure 8, "perfect" coreshell composite particles, indicated by the yellow arrows in Figures $8 \mathrm{~A}$ and $8 \mathrm{~B}$, were predominantly formed coexisting with worm-like micelles. Half-capped particles (white arrow in Figure 8B) could also be occasionally seen. The polymer worms appeared as independent nano-objects or as tails protruding from the silica surface. As mentioned above, 
such morphologies likely result from the fusion of the polymer latex particles formed in the early stages of the polymerization (either at the silica surface or in the water phase). Wormlike micelles being the predominant morphology in the absence of silica under these conditions, no other morphologies were observed in this sample.
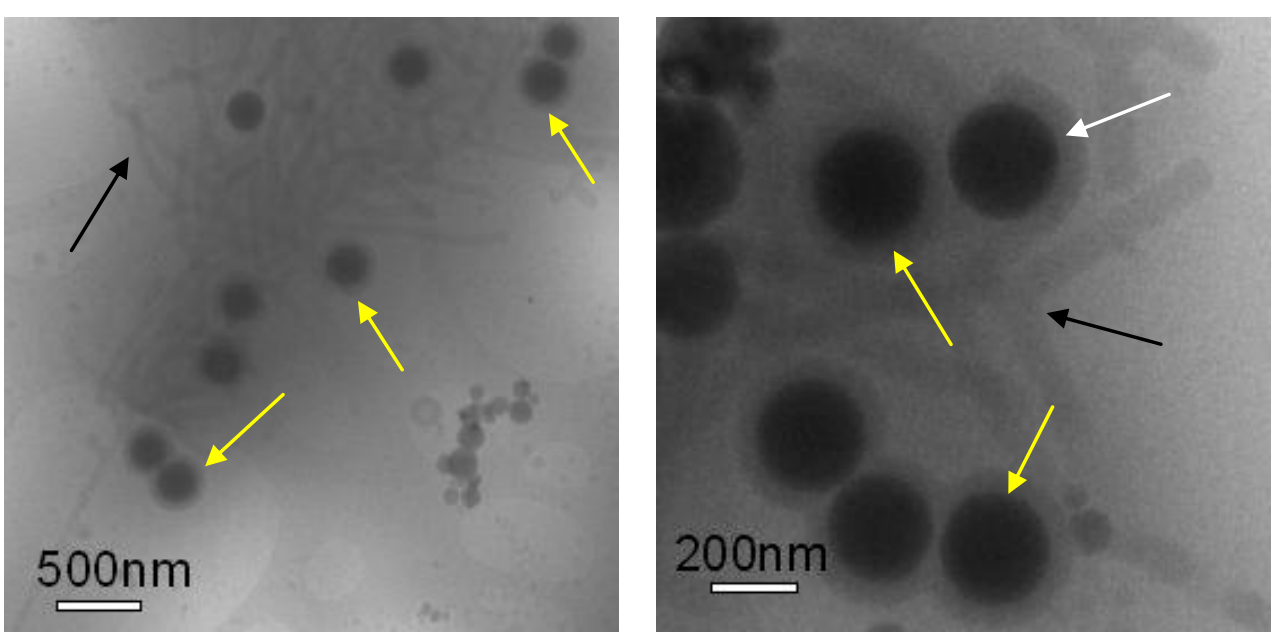

Figure 8. Cryo-TEM images of silica/polymer composites particles obtained by emulsion copolymerization of BMA and $\mathrm{S}$ carried out at $\mathrm{pH} 8.2$ in the presence of $230 \mathrm{~nm}$ diameter silica particles using $\mathrm{P}\left[\left(\mathrm{PEOMA}_{950}\right)_{12}-\mathrm{co}-\mathrm{S}_{1}\right]-\mathrm{SG} 1$ as macroinitiator (EH05 in Table 1$)$. The arrows point to the protruding polymer worms (black) and to core-shell (yellow) or halfcapped (white) morphologies, respectively.

Figure 9 shows the morphology obtained for smaller silica particles $\left(D_{\mathrm{n}}=30 \mathrm{~nm}, \mathrm{EH} 06\right.$, Table 1) still under basic conditions ( $\mathrm{pH}$ 8.0). Interestingly, a centipede-like structure was formed. These hybrid particles consisted of polymer worms that were decorated by silica particles with a second, spherical polymer nodule. Similarly, polymer vesicles decorated with silica particles with a second spherical nodule, were also observed. In both cases, most of the spherical polymer latex particles were in direct contact with the silica particles although a few of them also appeared free in water. As before, such morphologies can be attributed to the PISA process. As vesicles and worms are formed by the fusion of spherical latex particles 
obtained at very low conversions, the presence of residual latex particles at the surface of the silica-armored fibers and/or vesicles suggests that these higher-order morphologies originate from the fusion of polymer nodules between dipods or tripods of silica particles and polymer spheres. Not all of the polymer nodules are involved during the sphere-to-worm and wormto-vesicle transitions which results in a hybrid morphology with a $2^{\text {nd }}$ order hierarchical structure. Such dipod or tripod assemblies were indeed the predominant morphologies for low silica particle size using $1.6 \mathrm{mM}$ of macroinitator below $\mathrm{pH} 6{ }^{15}$
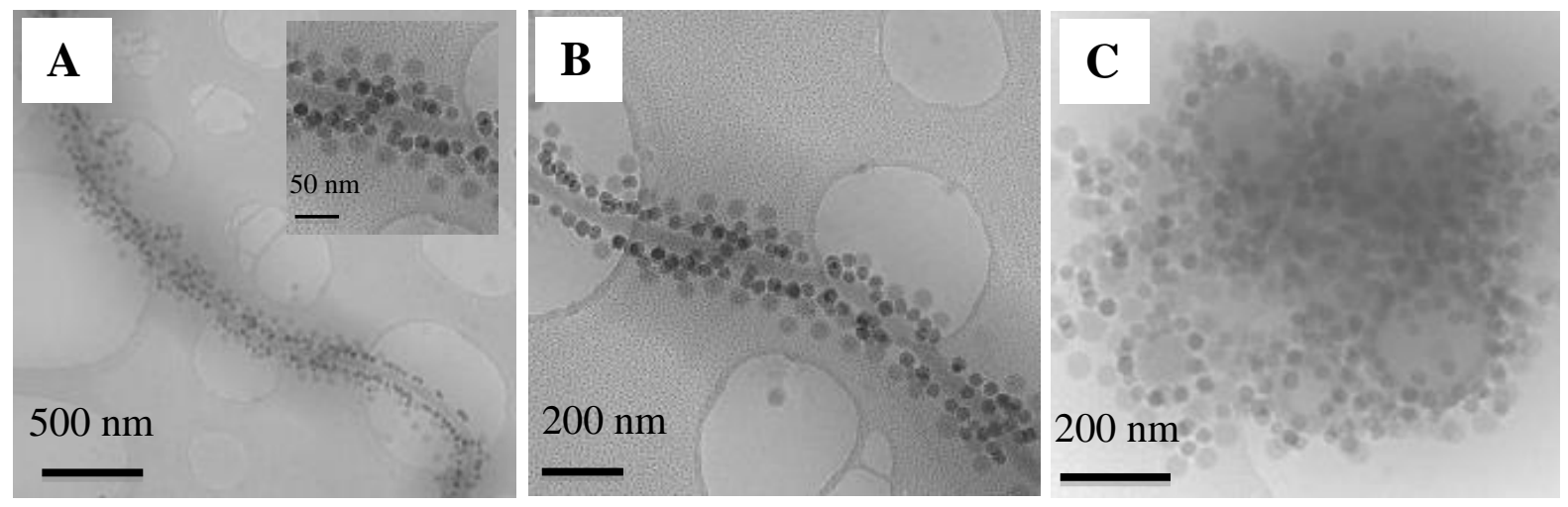

Figure 9. Cryo-TEM images of silica/polymer composite latex particles obtained by emulsion copolymerization of BMA and $\mathrm{S}$ carried out at $\mathrm{pH} 8.0$ in the presence of $30 \mathrm{~nm}$ diameter silica particles using $\mathrm{P}\left[\left(\mathrm{PEOMA}_{950}\right)_{12}-\mathrm{co}-\mathrm{S}_{1}\right]-\mathrm{SG} 1$ as macroinitiator (EH06 in Table 1). (A, B) Silica-armored worm-like micelles and (C) silica-armored vesicles.

The silica-armored vesicles of Figure 9C are reminiscent of the hybrid vesicle morphology reported earlier by Semsarilar et $a l .{ }^{41}$ during electrostatic adsorption of cationic alumina-coated silica particles onto anionic vesicles, made by PISA. However, to the best of our knowledge, this is the first time that such a morphology is realized by in situ selfassembly of BCPs at the surface of silica particles in a one-step procedure. On a related note, Mable and co-workers ${ }^{19}$ recently reported the successful encapsulation of silica nanoparticles within the lumen of diblock copolymer vesicles prepared via PISA. However, unlike the 
present work, the macroRAFT agents synthesized by Mable et al. did not display any physico-chemical interaction with the silica particles, and encapsulation was the direct consequence of the self-assembly process that enabled the silica particles to diffuse within the jellyfish before the completion of membrane formation. In the present work, macroinitiator adsorption at the silica surface favored the growth of polymer nodules, preventing the silica particles from being encapsulated as the latter were maintained adsorbed at the surface of the polymer worms and vesicles during the fusion process leading to silica-armored morphologies.

With the aim to encapsulate the silica particles into worm-like micelles or vesicles, they were functionalized by $\gamma$-methacryloxypropyl trimethoxysilane $(\gamma$-MPS) in order to promote encapsulation by covalent attachment of the formed polymer at the silica surface, as previously reported in the literature. ${ }^{42}$ The grafting was carried out in a hydroalcoholic medium at room temperature for $24 \mathrm{~h}$ and the grafting density was determined by TGA using equation S1 as described in the Supporting Information. We found a grafting density of 4.2 $\mu \mathrm{mol} \mathrm{m} \mathrm{m}^{-2}$, value in the same range as the highest values previously reported for similar grafting reactions, ${ }^{43,44}$ while FTIR confirmed the surface chemical modification with the presence of the carbonyl and methacrylate groups of the silane molecule (Figure S2 in the Supporting Information).

An emulsion polymerization experiment (EH07, Table 1) was then conducted in the presence of $\gamma$-MPS-functionalized silica particles at $\mathrm{pH} 5.2$, whose conditions should lead to the formation of spherical particles. As expected, polymer-encapsulated silica particles were produced under these conditions with several silica particles being surrounded by polymer (Figures 10A and 10B). 

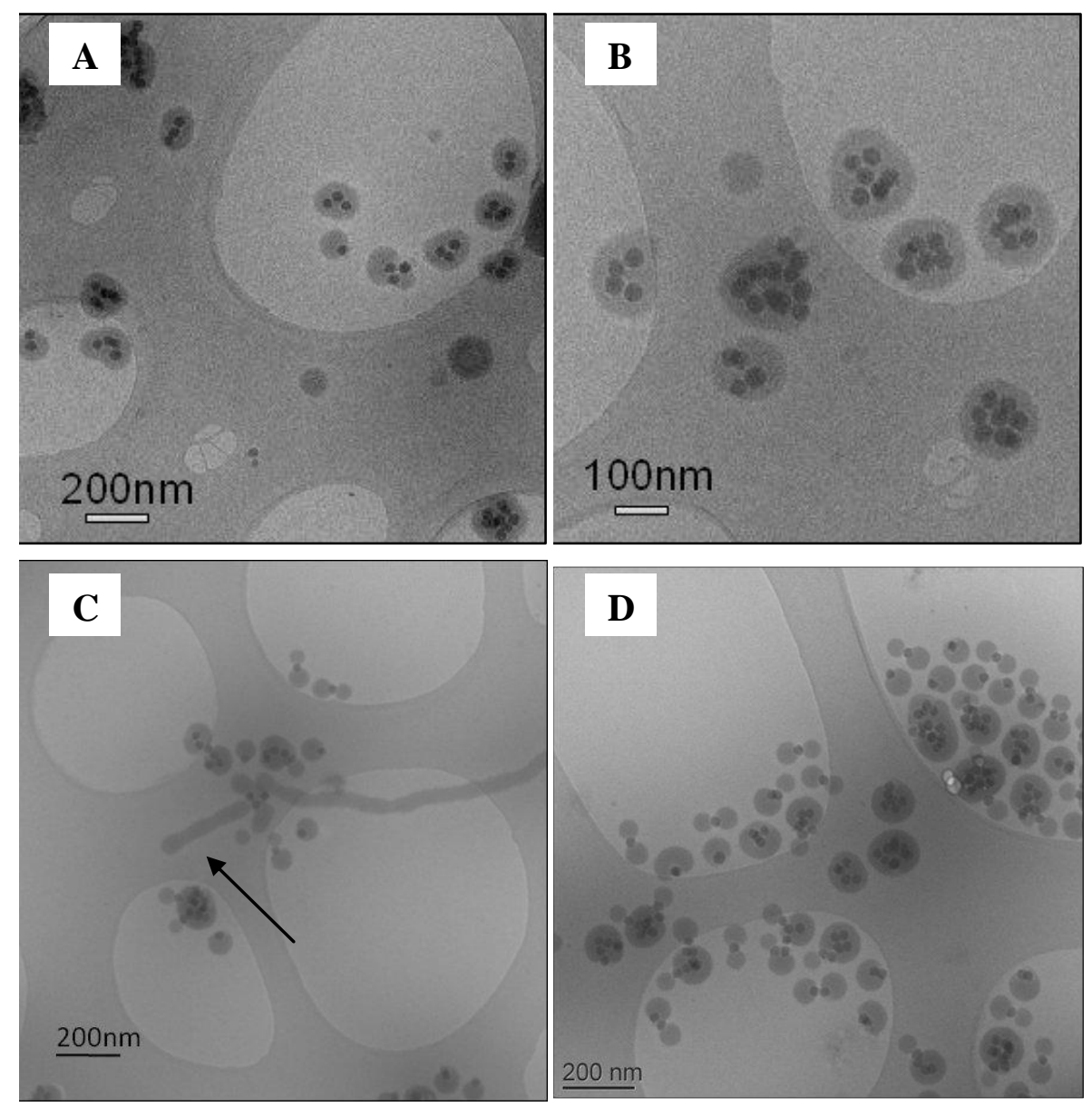

Figure 10. Cryo-TEM images of polymer-encapsulated silica particles obtained by emulsion copolymerization of BMA and S carried out in the presence of $\gamma$-MPS-functionalized silica particles $\left(D_{\mathrm{n}}=30 \mathrm{~nm}\right)$ using $\mathrm{P}\left[\left(\mathrm{PEOMA}_{950}\right)_{12}-c o-\mathrm{S}_{1}\right]-\mathrm{SG} 1$ as macroinitiator for different $\mathrm{pH}$ values. $(\mathrm{A}, \mathrm{B}) \mathrm{pH}=5.2(\mathrm{EH} 07)$ and $(\mathrm{C}, \mathrm{D}) \mathrm{pH}=8.1(\mathrm{EH} 08)$ (Table 1). The arrows point to worm-like micelles.

Another experiment was then performed at $\mathrm{pH} 8.1$ in order to favor the formation of worm-like micelles. However, as shown in Figures 10C and 10D, spheroidal polymerencapsulated silica particles were again observed together with some eccentric core-shell particles and a few dipods. On close inspection of Figure 10C, polymer fibers (indicated by black arrows) could also be occasionally seen, but these fibers did not contain any silica particle. One possible explanation for the failure to encapsulate silica particles into worm-like 
micelles and/or vesicles in the present system is the formation of covalent bonds between the silica particles and the growing polymer chains. Such chemical bonds would decrease the mobility of the self-assembled block copolymers and would consequently prevent them from fusing to generate elongated morphologies and/or vesicles, the silica particles playing somehow the role of a cross-linker. Indeed, several authors have shown that in situ crosslinking of nano-objects during PISA decreases molecular mobility preventing any morphological transition to take place..$^{45,46,47}$

\section{CONCLUSIONS}

In summary, we have investigated the effect of $\mathrm{pH}$ on the self-assembly behavior of $\mathrm{P}(\mathrm{PEOMA}-c o-\mathrm{S})-b-\mathrm{P}(\mathrm{BMA}-c o-\mathrm{S})$ diblock copolymers at the surface of colloidal silica particles of various diameters. A brush-type PEO-based macroalkoxyamine was selected to interact with the silica surface though hydrogen bonding, and further used as macroinitiator to control the growth of the hydrophobic block through NMP-mediated emulsion polymerization. Depending on the $\mathrm{pH}$ value and the silica particle size, nanocomposite particles with multipod-, concentric core-shell-corona, snowman-like vesicular, tadpole- and centipede-like morphologies were successfully achieved using P[(PEOMA $\left.\left.{ }_{950}\right)_{12}-c o-\mathrm{S}_{1}\right]-\mathrm{SG} 1$ as macroalkoxyamine. While very small silica particles led to armored fibers and/or vesicles, much larger particles resulted almost exclusively into core-shell structures. Interestingly, the use of an intermediate silica particle size led to a complex mixture of kinetically-trapped copolymer morphologies. Cryo-ET was used to better characterize these morphologies and capture the intermediate structures observed during particle synthesis providing clear evidence of the morphological transitions occurring at the silica surface, notably the sphereto-worm and worm-to-vesicle transitions, which significantly enhanced our understanding of the detailed mechanism of BCP self-assembly at the surface of inorganic particles. At last, 
our attempt to encapsulate functionalized silica particles into polymer worms was unsuccessful as the introduction of polymerizable moieties favored the formation of chemical bonds between the polymer chains and the silica surface, hindering morphological transitions in a similar way as when using a cross-linker. As far as we know, this is the first time that such mechanistic insights have been reported about the polymerization-induced self-assembly of block copolymers in the presence of inorganic particles.

\section{SUPPORTING INFORMATION}

The supporting information is available free of charge on the ACS Publications website at DOI:

SEC traces of the macroalcoxyamine initiator and of the final P(PEOMA- $c o-\mathrm{S})-b-\mathrm{P}(\mathrm{BMA}-$ $c o$-S) self-assembled block copolymers. Experimental conditions for $\gamma$-MPS grafting of the silica particles and FTIR characterization.

\section{ACKNOWLEDGMENTS}

The authors greatly acknowledge financial support from the Chinese Scholarship Council. They are grateful to Olivier Boyron $(\mathrm{C} 2 \mathrm{P} 2)$ for his assistance with SEC analyses. Arkema is thanked for kindly providing the BlockBuilder initiator and the SG1 nitroxide used in this work. Olivier Lambert and Jean-Christophe Taveau thank ANR "TOCOMO” and the conseil régional Aquitaine for partial financial support. The authors warmly thank Dr. Samuel Pearson and Dr. Ming Liang Koh for valuable suggestions and proofreading. 


\section{REFERENCES}

1. Bourgeat-Lami, E., Organic-inorganic nanostructured colloids. J. Nanosci. Nanotechnol. 2002, 2, 1-24.

2. Van Herk, A. M., Historical overview of (mini)emulsion polymerizations and preparation of hybrid latex particles. Adv. Polym. Sci. 2010, 233, 1-18.

3. Bourgeat-Lami, E.; Lansalot, M., Organic/Inorganic Composite Latexes: The Marriage of Emulsion Polymerization and Inorganic Chemistry. Adv. Polym. Sci. 2010, 233, 53-123.

4. Nguyen, D.; Zondanos, H. S.; Farrugia, J. M.; Serelis, A. K.; Such, C. H.; Hawkett, B. S., Pigment Encapsulation by Emulsion Polymerization Using Macro-RAFT Copolymers. Langmuir 2008, 24, 2140-2150.

5. Zetterlund, P. B.; Thickett, S. C.; Perrier, S.; Bourgeat-Lami, E.; Lansalot, M., Controlled/Living Radical Polymerization in Dispersed Systems: An Update. Chem. Rev. 2015, 115, 9745-800.

6. Bourgeat-Lami, E.; D’Agosto, F.; Lansalot, M., Synthesis of Nanocapsules and Polymer/Inorganic Nanoparticles Through Controlled Radical Polymerization At and Near Interfaces in Heterogeneous Media. Adv. Polym. Sci. 2016, 270, 123-161.

7. Zgheib, N.; Putaux, J.-L.; Thill, A.; Bourgeat-Lami, E.; D'Agosto, F.; Lansalot, M., Cerium oxide encapsulation by emulsion polymerization using hydrophilic macroRAFT agents. Polym. Chem. 2013, 4, 607-614.

8. Li, K.; Dugas, P.-Y.; Bourgeat-Lami, E.; Lansalot, M., Polymer-encapsulated $\gamma-$ Fe2O3 nanoparticles prepared via RAFT-mediated emulsion polymerization. Polymer 2016, 106, 249-260.

9. Bourgeat-Lami, E.; França, A. J. P. G.; Chaparro, T. C.; Silva, R. D.; Dugas, P. Y.; Alves, G. M.; Santos, A. M., Synthesis of Polymer/Silica Hybrid Latexes by Surfactant-Free RAFT-Mediated Emulsion Polymerization. Macromolecules 2016, 49, 4431-4440.

10. Zhong, W.; Zeuna, J. N.; Claverie, J. P., A versatile encapsulation method of noncovalently modified carbon nanotubes by RAFT polymerization. J. Polym. Sci., Part A: Polym. Chem. 2012, 50, 4403.

11. Huynh, V. T.; Nguyen, D.; Such, C. H.; Hawkett, B. S., Polymer coating of graphene oxide via reversible addition-fragmentation chain transfer mediated emulsion polymerization. J. Polym. Sci., Part A: Polym. Chem. 2015, 53, 1413-1421. 
12. Ali, S. I.; Heuts, J. P. A.; Hawkett, B. S.; van Herk, A. M., Polymer Encapsulated Gibbsite Nanoparticles: Efficient Preparation of Anisotropic Composite Latex Particles by RAFT-Based Starved Feed Emulsion Polymerization. Langmuir 2009, 25, 10523-10533.

13. Mballa Mballa, M. A.; Ali, S. I.; Heuts, J. P. A.; van Herk, A. M., Control of the anisotropic morphology of latex nanocomposites containing single montmorillonite clay particles prepared by conventional and reversible addition-fragmentation chain transfer based emulsion polymerization. Polym. Int. 2012, 61, 861-865.

14. Cenacchi, A.; Pearson, S.; Kostadinova, D.; Leroux, F.; D'Agosto, F.; Lansalot, M.; Bourgeat-Lami, E.; Prevot, V., Nanocomposite latexes containing layered double hydroxides via RAFT-assisted encapsulating emulsion polymerization. Polym. Chem. 2017, 8, 12331243.

15. Qiao, X. G.; Dugas, P. Y.; Charleux, B.; Lansalot, M.; Bourgeat-Lami, E., Synthesis of Multipod-like Silica/Polymer Latex Particles via Nitroxide-Mediated PolymerizationInduced Self-Assembly of Amphiphilic Block Copolymers. Macromolecules 2015, 48, 545556.

16. Loiko, O. P.; Spoelstra, A. B.; van Herk, A. M.; Meuldijk, J.; Heuts, J. P. A., An ATRP-based approach towards water-borne anisotropic polymer-Gibbsite nanocomposites. Polym. Chem. 2016, 7, 3383-3391.

17. Cenacchi-Pereira, A.; Grant, E.; D’Agosto, F.; Lansalot, M.; Bourgeat-Lami, E., Encapsulation with the Use of Controlled Radical Polymerization. In Encyclopedia of Polymeric Nanomaterials, Kobayashi, S.; Müllen, K., Eds. Springer Berlin Heidelberg: 2015; pp 718-729.

18. Rodrigues Guimarães, T.; de Camargo Chaparro, T.; D'Agosto, F.; Lansalot, M.; Martins Dos Santos, A.; Bourgeat-Lami, E., Synthesis of multi-hollow clay-armored latexes by surfactant-free emulsion polymerization of styrene mediated by poly(ethylene oxide)based macroRAFT/Laponite complexes. Polym. Chem. 2014, 5, 6611-6622.

19. Mable, C. J.; Gibson, R. R.; Prevost, S.; McKenzie, B. E.; Mykhaylyk, O. O.; Armes, S. P., Loading of Silica Nanoparticles in Block Copolymer Vesicles during PolymerizationInduced Self-Assembly: Encapsulation Efficiency and Thermally Triggered Release. J. Am. Chem. Soc. 2015, 137, 16098-16108.

20. Canning, S. L.; Smith, G. N.; Armes, S. P., A Critical Appraisal of RAFT-Mediated Polymerization-Induced Self-Assembly. Macromolecules 2016, 49, 1985-2001. 
21. Rieger, J., Guidelines for the Synthesis of Block Copolymer Particles of Various Morphologies by RAFT Dispersion Polymerization. Macromol. Rapid Commun. 2015, 36, $1458-1471$.

22. Derry, M. J.; Fielding, L. A.; Armes, S. P., Polymerization-induced self-assembly of block copolymer nanoparticles via RAFT non-aqueous dispersion polymerization. Prog. Polym. Sci. 2016, 52, 1-18.

23. Lesage de la Haye, J.; Zhang, X.; Chaduc, I.; Brunel, F.; Lansalot, M.; D'Agosto, F., The Effect of Hydrophile Topology in RAFT-Mediated Polymerization-Induced SelfAssembly. Angew. Chemie Int. Ed. 2016, 55, 3739-3743.

24. Qiao, X. G.; Lansalot, M.; Bourgeat-Lami, E.; Charleux, B., Nitroxide-Mediated Polymerization-Induced Self-Assembly of Poly(poly(ethylene oxide) methyl ether methacrylate-co-styrene)-b-poly(n-butyl methacrylate-co-styrene) Amphiphilic Block Copolymers. Macromolecules 2013, 46, 4285-4295.

25. Hartlen, K. D.; Athanasopoulos, A. P. T.; Kitaev, V., Facile Preparation of Highly Monodisperse Small Silica Spheres (15 to >200 nm) Suitable for Colloidal Templating and Formation of Ordered Arrays. Langmuir 2008, 24, 1714-1720.

26. Giesche, H., Synthesis of monodispersed silica powders II. Controlled growth reaction and continuous production process. J. Eur. Ceram. Soc. 1994, 14, 205-214.

27. Stöber, W.; Fink, A.; Bohn, E., Controlled growth of monodisperse silica spheres in the micron size range. J. Colloid Interface Sci. 1968, 26, 62-69.

28. Mastronarde, D. N., Dual-Axis Tomography: An Approach with Alignment Methods That Preserve Resolution. J. Struct. Biol. 1997, 120, 343-352.

29. Chen, H.; Hughes, D. D.; Chan, T.-A.; Sedat, J. W.; Agard, D. A., IVE (Image Visualization Environment): A Software Platform for All Three-Dimensional Microscopy Applications. J. Struct. Biol. 1996, 116, 56-60.

30. Desert, A.; Chaduc, I.; Fouilloux, S.; Taveau, J.-C.; Lambert, O.; Lansalot, M.; Bourgeat-Lami, E.; Thill, A.; Spalla, O.; Ravaine, S.; Duguet, E., High-yield preparation of polystyrene/silica clusters of controlled morphology. Polym. Chem. 2012, 3, 1130-1132.

31. Desert, A.; Morele, J.; Taveau, J.-C.; Lambert, O.; Lansalot, M.; Bourgeat-Lami, E.; Thill, A.; Spalla, O.; Belloni, L.; Ravaine, S.; Duguet, E., Multipod-like silica/polystyrene clusters. Nanoscale 2016, 8, 5454-5469.

32. Blanazs, A.; Madsen, J.; Battaglia, G.; Ryan, A. J.; Armes, S. P., Mechanistic Insights for Block Copolymer Morphologies: How Do Worms Form Vesicles? J. Am. Chem. Soc. 2011, 133, 16581-16587. 
33. de Jong, K. P.; Koster, A. J., Three-Dimensional Electron Microscopy of Mesoporous Materials-Recent Strides Towards Spatial Imaging at the Nanometer Scale. Chem. Phys. Chem. 2002, 3, 776-780.

34. Weyland, M.; Yates, T. J. V.; Dunin-Borkowski, R. E.; Laffont, L.; Midgley, P. A., Nanoscale analysis of three-dimensional structures by electron tomography. Scripta Mater. 2006, 55, 29-33.

35. Midgley, P. A.; Weyland, M., 3D electron microscopy in the physical sciences: the development of Z-contrast and EFTEM tomography. Ultramicroscopy 2003, 96, 413-431.

36. Kaneko, K.; Moon, W.-J.; Inoke, K.; Horita, Z.; Ohara, S.; Adschiri, T.; Abe, H.; Naito, M., Characterization of $\mathrm{TiO} 2-\mathrm{Ag}$ nanocomposite particles prepared by spray pyrolysis process using transmission electron microscopy and three-dimensional electron tomography. Mater. Sci. Eng. 2005, 403, 32-36.

37. Midgley, P. A.; Weyland, M.; Yates, T. J. V.; Arslan, I.; Dunin-Borkowski, R. E.; Thomas, J. M., Nanoscale scanning transmission electron tomography. J. Microsc. 2006, 223, 185-190.

38. Kaneko, K.; Nagayama, R.; Inoke, K.; Moon, W. J.; Horita, Z.; Hayashi, Y.; Tokunaga, T., Formation of wedge-shaped carbon film by chemical vapor deposition method and observation using transmission electron microscopy. Scripta Mater. 2005, 52, 12051209.

39. Kohjiya, S.; Katoh, A.; Shimanuki, J.; Hasegawa, T.; Ikeda, Y., Three-dimensional nano-structure of in situ silica in natural rubber as revealed by 3D-TEM/electron tomography. Polymer 2005, 46, 4440-4446.

40. Parry, A. L.; Bomans, P. H. H.; Holder, S. J.; Sommerdijk, N. A. J. M.; Biagini, S. C. G., Cryo Electron Tomography Reveals Confined Complex Morphologies of TripeptideContaining Amphiphilic Double-Comb Diblock Copolymers. Angew. Chemie Int. Ed. 2008, $47,8859-8862$.

41. Semsarilar, M.; Jones, E. R.; Blanazs, A.; Armes, S. P., Efficient Synthesis of Sterically-Stabilized Nano-Objects via RAFT Dispersion Polymerization of Benzyl Methacrylate in Alcoholic Media. Adv. Mater. 2012, 24, 3378-3382.

42. Bourgeat-Lami, E.; Insulaire, M.; Reculusa, S.; Perro, A.; Ravaine, S.; Duguet, E., Nucleation of polystyrene latex particles in the presence of gamma-methacryloxypropyltrimethoxysilane: Functionalized silica particles. J. Nanosci. Nanotechnol. 2006, 6, 432-444. 
43. Bourgeat-Lami, E.; Espiard, P.; Guyot, A.; Gauthier, C.; David, L.; Vigier, G., Emulsion polymerization in the presence of colloidal silica particles - Application to the reinforcement of poly(ethyl acrylate) films. Angew. Makromolek. Chem. 1996, 242, 105-122. 44. Bourgeat-Lami, E.; Farzi, G. A.; David, L.; Putaux, J.-L.; McKenna, T. F. L., Silica Encapsulation by Miniemulsion Polymerization: Distribution and Localization of the Silica Particles in Droplets and Latex Particles. Langmuir 2012, 28, 6021-6031.

45. Sugihara, S.; Armes, S. P.; Blanazs, A.; Lewis, A. L., Non-spherical morphologies from cross-linked biomimetic diblock copolymers using RAFT aqueous dispersion polymerization. Soft Matter 2011, 7, 10787-10793.

46. Qu, Q.; Liu, G.; Lv, X.; Zhang, B.; An, Z., In Situ Cross-Linking of Vesicles in Polymerization-Induced Self-Assembly. ACS Macro Letters 2016, 5, 316-320.

47. Lovett, J. R.; Ratcliffe, L. P. D.; Warren, N. J.; Armes, S. P.; Smallridge, M. J.; Cracknell, R. B.; Saunders, B. R., A Robust Cross-Linking Strategy for Block Copolymer Worms Prepared via Polymerization-Induced Self-Assembly. Macromolecules 2016, 49, 2928-2941. 
Nitroxide-mediated polymerization-induced self-assembly of block copolymers at the surface of silica particles:

Towards new hybrid morphologies

\author{
X. G. Qiao, ${ }^{1,2}$ O. Lambert, ${ }^{3}$ J-C. Taveau, ${ }^{3}$ P-Y. Dugas,,${ }^{1}$ B. Charleux, ${ }^{1}$ M. Lansalot,${ }^{1}$ \\ E. Bourgeat-Lami ${ }^{1 *}$
}

FOR TABLE OF CONTENTS GRAPHIC ONLY

\title{
SURFACE PISA
}

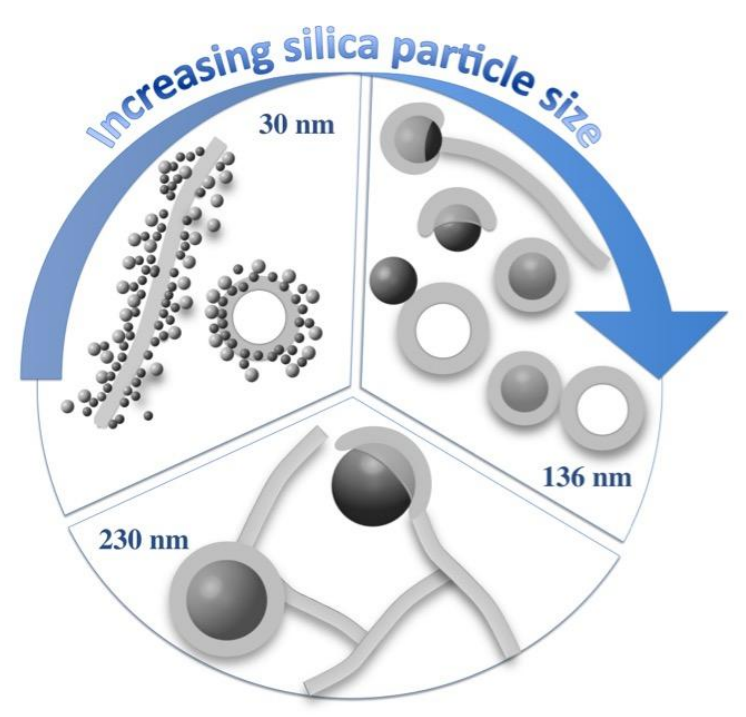

